\title{
Intervention cost optimization of bracing systems with multiperformance criteria
}

\author{
F. Braga, R. Gigliotti, R. Laguardia* \\ "Sapienza” University of Rome, Italy
}

\section{ARTICLE INFO}

\section{Keywords:}

Bracing

Energy dissipation

Optimization

Retrofit

Multiperformance

\begin{abstract}
A B S T R A C T
In this paper a multiperformance optimization procedure to design dissipative bracing systems controlling the structural performance while minimizing the intervention cost is proposed. The procedure allows dimensional and topological optimization of bracing, considering inelastic behaviour of braced structures through properly developed visco-elastic equivalent linearization schemes. The structural behaviour is controlled through constraint functions on interstory drift ratio (IDR) while the intervention cost is explicitly encountered by considering real costs that mainly influence it. The procedure is suitable for both new and existing structures, however the objective function is specialized on typical costs of retrofit interventions. A numerical example on a multistory frame has been developed in order to show the effectiveness of the procedure to provide the optimal characteristics and arrangement for the braces, while the suitability of linear equivalent schemes to predict the structural response is investigated through Nonlinear dynamic analyses. Further, a comparison of the estimated intervention costs by asking for different performance levels is performed, showing how the proposed objective function is able to help the designers to identify the ideal performance levels and acceptance criteria to reduce the cost-benefit ratio.
\end{abstract}

\section{Introduction}

The scientific interest on the seismic protection of existing buildings is continuously growing in these years, mainly due to the need of adapting the existing retrofit design methodologies to the modern approaches based on seismic risk assessment. In the recent years many seismic events hit densely populated areas (L'Aquila 2009, Italy; Christchurch 2011, New Zealand; Tohoku 2011, Japan; Emilia 2012, Italy; Centro Italia 2016, Italy), causing very high economic losses, besides fatalities and injuries [1-5]. The reconstruction costs of damaged buildings have been very high [6-8] and in some cases non-sustainable by communities [9]. Such relevant sequence of seismic events has shown up the inadequacy of the existing building heritage and the consequent need of extensive retrofit interventions or demolition and reconstruction. The lack of financial capacity for both public and private investments lead to the need of developing decision making tools to help authorities and stakeholders to assume decisions through risk assessments. For these reasons, in the recent years, new methodologies based on seismic risk assessments are substituting traditional performance based approaches [10-13]. The aim of seismic risk assessment is to estimate the economic losses during the lifecycle of an asset (i.e., building, bridge, productive activity, infrastructure, city, country etc.).
From a practical point of view, in the case of buildings, this usually means the calculation of structural response and consequent economical losses due to events with several frequencies of occurrence. In this logic, a retrofit intervention is profitable only if its cost is adequately proportional to the foreseen reduction of damages, in other words, the choice of type and properties of retrofit interventions should be made by explicitly considering the cost-benefit ratio. With this aim, a design procedure able to control both structural response for several action levels and intervention cost is needed, also due to the lack of methodologies aimed at controlling both these aspects at the same time.

The development of a design methodology with these features is feasible, in general, with several intervention techniques, however, bracing intervention has the advantage of being broadly adaptable to any performance request and it is therefore one of the most suitable technique to find an optimal trade-off between invasiveness (even in terms of cost) and structural performances. Retrofit interventions through bracing elements allow to stiffen the structural behaviour and to reduce the demand on the structural elements that need to be protected. Traditional design strategies aim to reduce such demand below damage thresholds, even for ultimate limit states action levels. As an alternative, design strategies that admit low or null damage for service limit states and moderate damages for higher action levels can be adopted. Therefore, through an appropriate selection of acceptance cri-

Email addresses: franco.braga@uniroma1.it (F. Braga); rosario.gigliotti@uniroma1.it (R. Gigliotti); raffaele.laguardia@uniroma1.it (R. Laguardia*) 


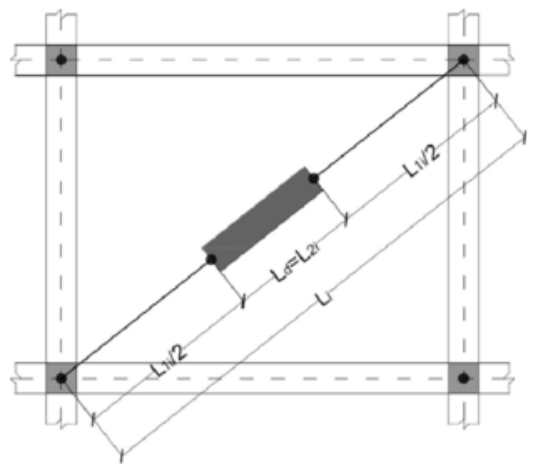

(a)

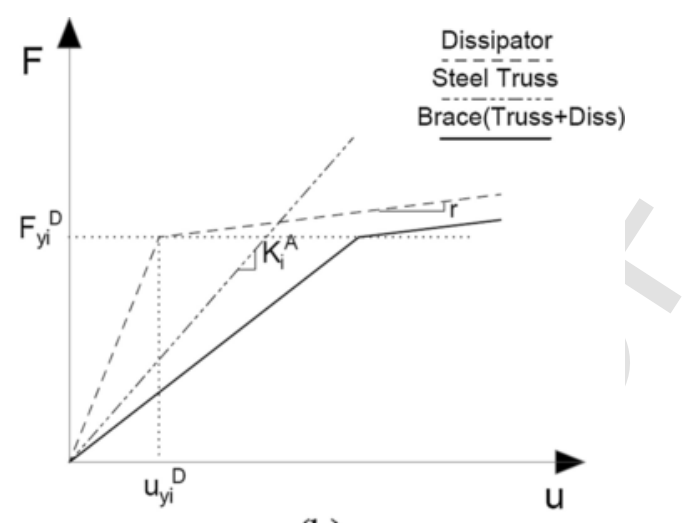

(b)

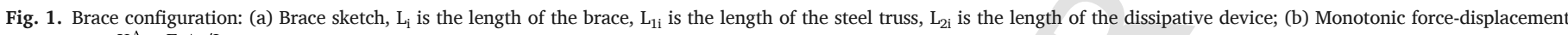
relationship, $\mathrm{K}_{\mathrm{i}}^{\mathrm{A}}=\mathrm{E}_{\mathrm{s}} \mathrm{A}_{\mathrm{i}} / \mathrm{L}_{\mathrm{li}}$ is the stiffness of the steel truss and $\mathrm{E}_{\mathrm{s}}$ is the elastic modulus of the steel.

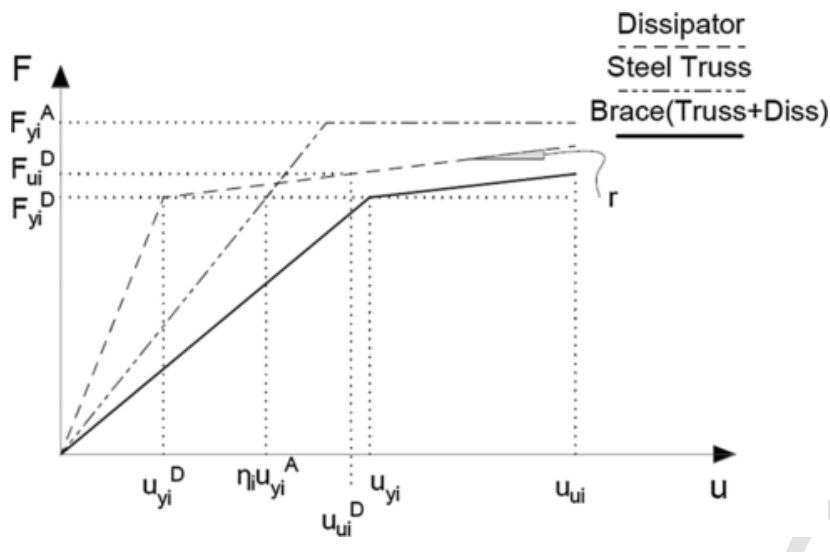

Fig. 2. Sketch of the force-displacement relationship expressed through the independent variables.

teria for the engineering demand parameters, it is possible to define an intervention balanced in terms of invasiveness and effectiveness, that can also avoid the need of local intervention reinforcements.

In the recent years, many new retrofit techniques and technologies based on stiffening and energy dissipation have been developed [14-16] highlighting the strong interest on this technique which allows to work on limited portions of the structure with low invasiveness. Because of its high potentiality, numerous design procedures and methodologies are available in the scientific literature for bracing systems. In some cases, the design of the bracing system is obtained by pursuing an optimality criterion (e.g., maximizing dissipated energy, minimizing interstory drift or base shear) while, in other cases, the design is performed through simplified methods (e.g. SDOF equivalent model). Among the methodologies which foresee an optimization, the most interesting, in terms of used techniques or effectiveness, can be listed as follows: Filiatrault and Cherry [17] proposed a procedure in order to obtain the design of friction devices with the goal of maximizing a damage index (RPI); Braga and D'Anzi [18] proposed a method to control the maximum displacement and the stress distribution in the structural elements while minimizing the steel volume needed for the intervention; Ciampi et al. [19] developed a procedure to control the kinematic ductility of the structure, maximizing the ratio between dissipated and input energies; Takewaki [20] used, as objective function, the modulus of the transfer function of the sum of the interstory drift valued at the natural frequency of the structure while constraining the maximum dissipated energy; Levy et al. [21] developed a two-step iterative method, optimizing damping and stiffness values and controlling the maximum displacement of the structure; Lavan and Dargush [22] proposed a multi-objective optimization method based on the use of (a)

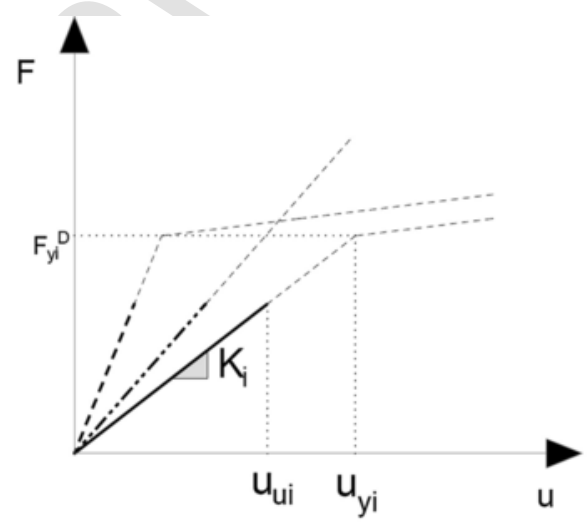

(b)

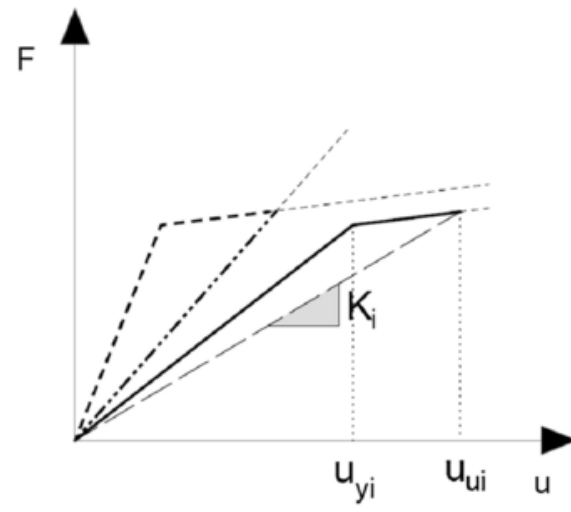

\section{Dissipator Steel Truss Brace(Truss+Diss)}

Fig. 3. Iterative linearization procedure, force displacement relationship: (a) Elastic brace, (b) Inelastic brace. Where $\mathrm{K}_{\mathrm{i}}^{\mathrm{A}}$ is the stiffness of the steel truss, $\mathrm{K}_{\mathrm{i}}^{\mathrm{D}}$ is the equivalent stiffness of the dissipator, $\mathrm{K}_{\mathrm{i}}$ is the equivalent stiffness of the brace and $\mathrm{E}_{\mathrm{i}}$ is the energy dissipated by the brace.

genetic algorithms and controlling interstory drift and peak floor accelerations; Pollini et al. [23,24] proposed an optimization procedure based on minimization of intervention costs that take into account topology and sizes of dampers and constraining the interstory drift ratios; Lavan and Wilkinson [25] proposed an optimization procedure based on the minimization of the moment capacity of all seismic members and by controlling the maximum interstory drift ratios for several action levels through a multiperformance approach. Among the proce- 


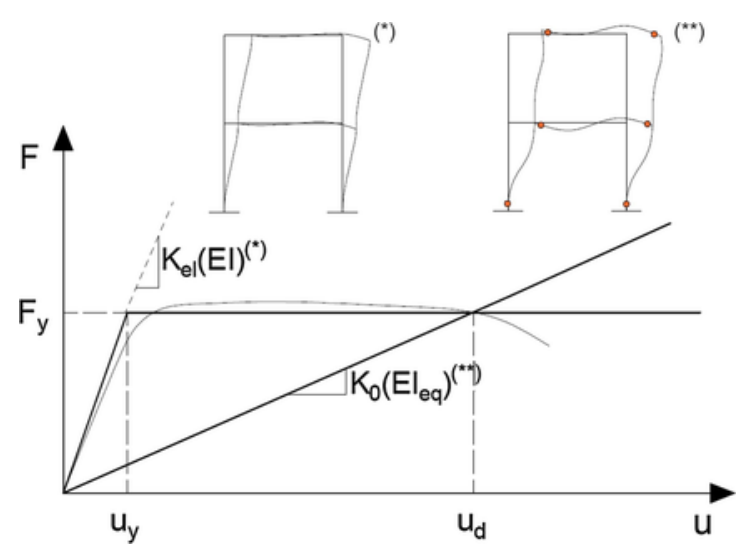

Fig. 4. Scheme of the initial stiffness matrix assessment, based on final displacement $\mathrm{u}_{\mathrm{d}}$.

dures that doesn't consider any optimality criterion, the following should be considered of interest: Inaudi et al. [26] proposed a preliminary design method for dampers based on an equivalent linearization of structural behaviour; Fu and Cherry [27] proposed a quasi-static procedure based on dedicated design spectra which allow to control maximum displacement and maximum base shear of the structure; Ramirez et al. [28] developed a procedure which uses an equivalent lateral force method where several vibration modes are kept in count through the use of a "residual" mode; Mazza and Vulcano [29] proposed a procedure which allows to limit maximum displacement of the structure and suggests to distribute the bracing characteristic along the height basing on the first modal shape of the existing structure; Wen et al.[30] realized several design spectra in order to obtain the sizing of elastoplastic or viscoelastic devices controlling maximum displacement, base shear, residual drift and maximum accelerations. These design procedures have been, in general, developed within a traditional performance based approach where the performance and optimization criteria are expressed in terms of traditional engineering demand parameters (EDP) such as interstory drift ratio (IDR), maximum roof displacement, maximum base shear or dissipated energy. Nevertheless, only few of the described methodologies allow to consider explicitly the cost intervention and there is a lack of methods aiming to seismic risk mitigation and cost-benefit analysis. Furthermore, among the procedures that foreseen an optimality criterion, the inelastic behaviour is kept in count through an explicit modelling and executing nonlinear analyses.

The proposed procedure aims to partially fill the gap between existing bracing design procedures and the most modern performance-based approaches, with this aim it allows to overlap a traditional multiperfor- mance approach with a specific assessment of cost intervention. The final objective is, thus, to identify which bracing system configuration guarantees the structural performances required by the different action levels and corresponds to the lowest final cost. This goal is achieved by developing an optimization procedure with an objective function that explicitly describes the intervention costs and by modelling the structural behaviour through equivalent linear schemes, considering brace yieldings and slight damages on the frame. In this way, reliable assessments on the structural behaviour of retrofitted structures can be obtained by defining few parameters and by performing simple elastic linear analyses with low computational effort, as it is desirable for a design method. Finally, beyond the linearizations, no further modelling simplifications are done and the specific formalization of the procedure allows to obtain the plan and elevation arrangement of the braces and their mechanical properties, with a topological optimization too. These properties, joined with the intervention cost assessment, help the designer to easily analyse many possible performance strategies, in order to find an optimal trade-off between invasiveness and effectiveness of intervention for each analysed building.

\section{Optimization procedure}

The proposed optimization procedure aims to define the mechanical properties and topological distribution of dissipative braces in order to obtain the desired structural performance with the least cost solution. Such procedure aims to solve an optimization problem, Eq. (1), where the objective function describes the real intervention cost and the constraint functions limit the values of the Interstory Drift Ratio (IDR)

$\min$

$$
\begin{aligned}
& O . F .(\mathbf{x}) \\
& \left\{\mathbf{h}_{\mathbf{u}}(\mathbf{x})=\mathbf{I D R}(\mathbf{x})-\mathbf{I D R}^{L i m} \leqslant 0\right.
\end{aligned}
$$

where O.F. is the objective function, $\mathbf{x}$ is the vector of the independent variables, $\mathbf{h}_{\mathbf{u}}$ is the vector of constraints, IDR is the vector that collects the IDR of each floor of the structure for a given seismic action and IDR $^{\text {Lim }}$ is the vector of acceptance criteria on IDR for each floor.

In this section, the principal parts of the procedure are formalized. The independent variables of the problem (i.e. the quantities objective of the design) are presented as first. Then, the structural models adopted for the braces and for the reinforced concrete frame are shown, with particular regard to the linearization schemes adopted and with focus on the assembly of the stiffness matrix and equivalent damping ratio. Subsequently, the constraint functions of the problem and the proposed objective function that allows the minimizations of intervention costs are presented.

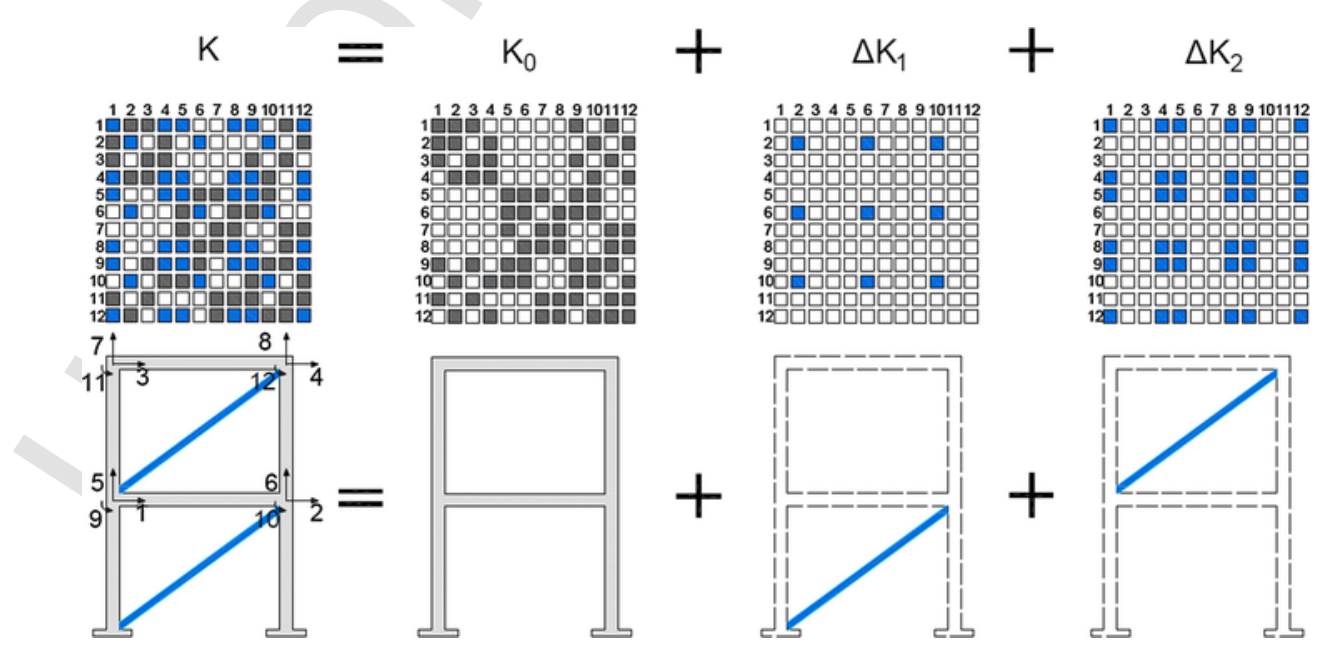

Fig. 5. Example of global matrix assembly. Braced structure stiffness matrix, $\mathbf{K}$, unbraced structure stiffness matrix, $\mathbf{K}_{0}$, and contribution of the single braces, $\Delta \mathbf{K}_{1}$ and $\Delta \mathbf{K}_{2}$. 


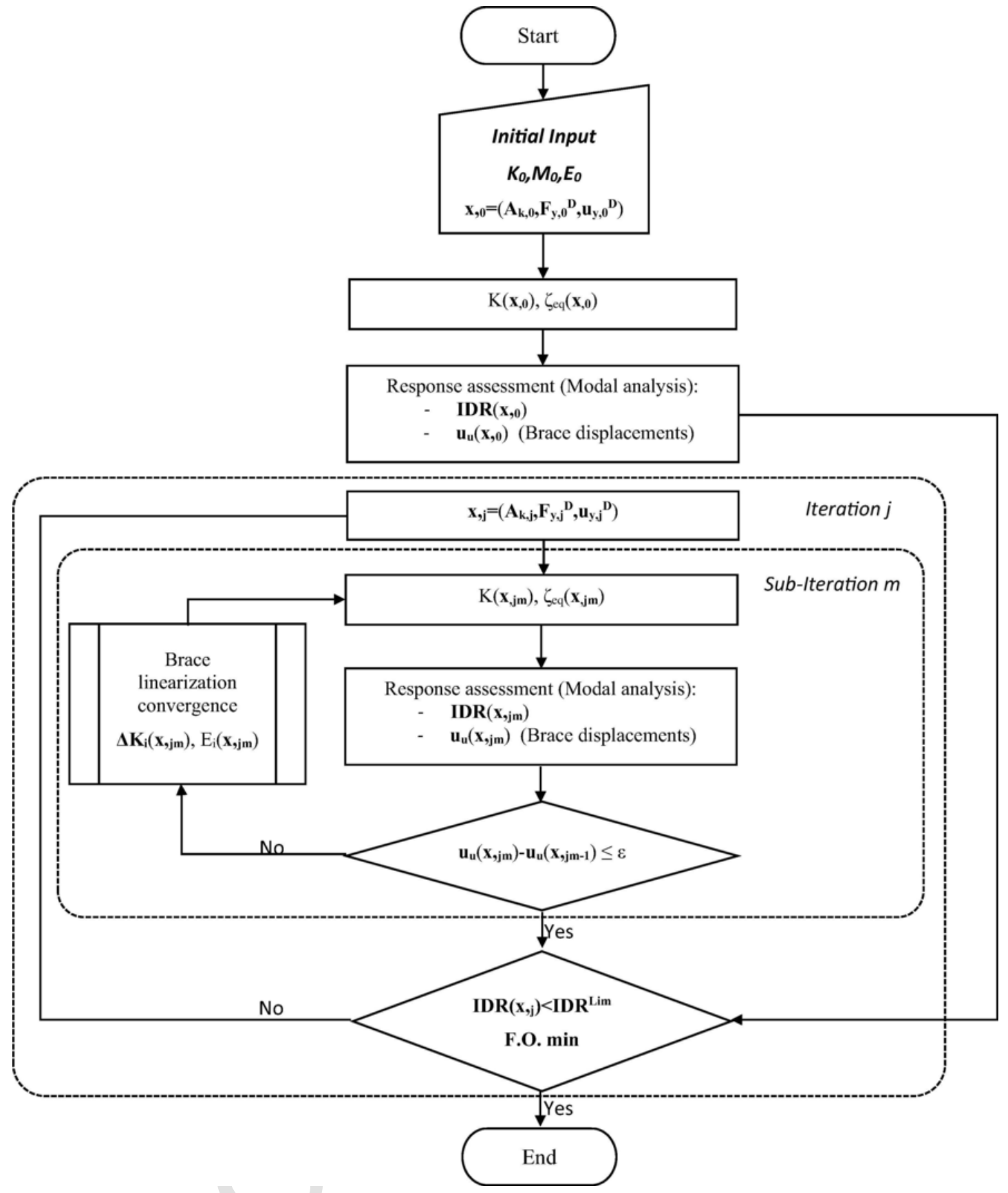

Fig. 6. Flowchart of the procedure.

\subsection{Independent variables}

The independent variables of the optimization problem are chosen in order to describe the backbone curve of the brace and to be similar to the commonly required parameters for braces design in engineering applications. The adopted bracing scheme is composed by a steel truss pinned to the frame in series with an elastoplastic dissipative device (Fig. 1a). The monotonic force-displacement relationship of the brace is evaluated considering a bilinear behaviour of the dissipating device while the truss is assumed to behave elastically (Fig. 1b). Given a structure with $n$ braces, the independent variables can be formalized as

$\mathbf{A}_{K}=[\mathrm{n} \times 1]=\left[\begin{array}{llllll}A_{1} & A_{2} & \ldots & A_{\mathrm{i}} & \ldots & A_{\mathrm{n}}\end{array}\right]$

(2)

$$
\begin{aligned}
& \mathbf{F}_{\mathbf{y}}^{\mathbf{D}}=[\mathrm{n} \times 1]=\left[\begin{array}{llllll}
\mathrm{F}_{\mathrm{y} 1}^{\mathrm{D}} & \mathrm{F}_{\mathrm{y} 2}^{\mathrm{D}} & \ldots & \mathrm{F}_{\mathrm{yi}}^{\mathrm{D}} & \ldots & \mathrm{F}_{\mathrm{yn}}^{\mathrm{D}}
\end{array}\right] \\
& \mathbf{u}_{\mathbf{y}}^{\mathbf{D}}=[\mathrm{n} \times 1]=\left[\begin{array}{llllll}
\mathrm{u}_{\mathrm{y} 1}^{\mathrm{D}} & \mathrm{u}_{\mathrm{y} 2}^{\mathrm{D}} & \ldots & \mathrm{u}_{\mathrm{yi}}^{\mathrm{D}} & \ldots & \mathrm{u}_{\mathrm{yn}}^{\mathrm{D}}
\end{array}\right] \\
& \mathbf{x}=\left[\begin{array}{lll}
\mathbf{A}_{\mathbf{K}} & \mathbf{F}_{\mathbf{y}}^{\mathbf{D}} & \mathbf{u}_{\mathbf{y}}^{\mathbf{D}}
\end{array}\right]
\end{aligned}
$$

The i-th component of $\mathbf{A}_{\mathbf{K}}, \mathbf{F}_{\mathbf{y}} \mathbf{D}$ and $\mathbf{u}_{\mathbf{y}}{ }^{\mathbf{D}}$ describes the characteristics of the generic $\mathrm{i}$-th brace of the structure, respectively as the area of each steel truss, $\mathrm{A}_{\mathrm{i}}$, the yielding force, $\mathrm{F}_{\mathrm{yi}} \mathrm{D}$, and the yielding displacement, $\mathrm{u}_{\mathrm{yi}} \mathrm{D}$ of each dissipator, while the hardening ratio $\mathrm{r}$ is fixed. 


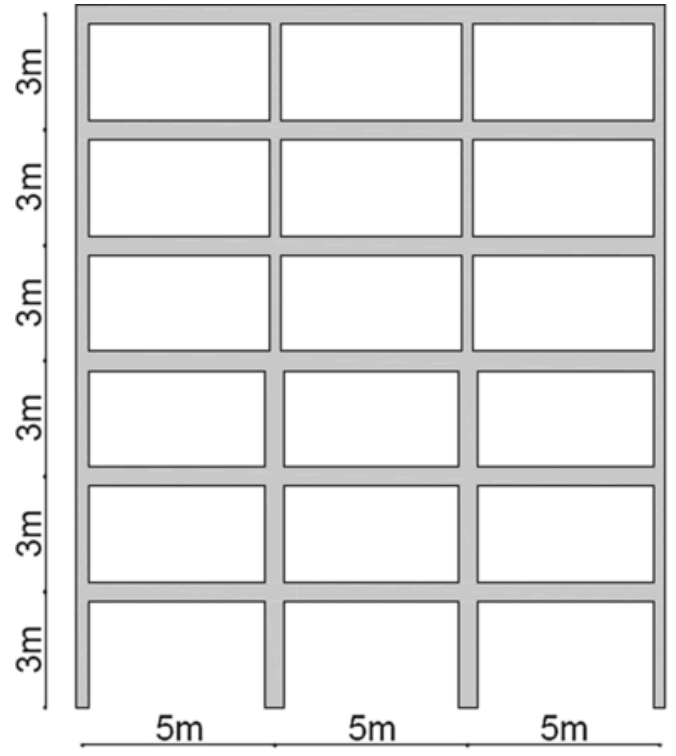

Fig. 7. Case study adopted for the numerical example.

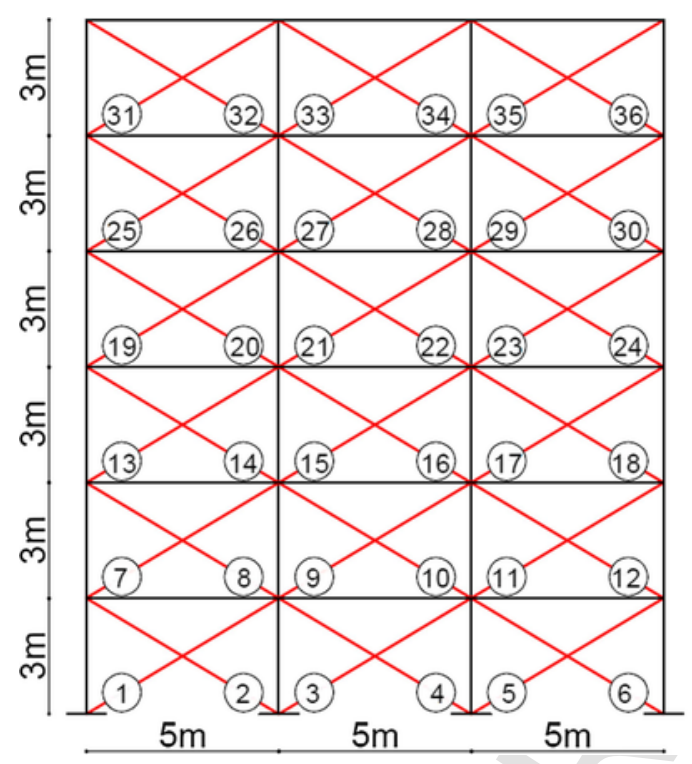

Fig. 8. Initial Brace arrangement.

\subsection{Brace model and linearization}

By using the hypothesis and notations adopted for the definition of the independent variables, the complete force-displacement relationship of the brace (sketched in Fig. 2) can be expressed through the following equations

$$
\begin{gathered}
\mathrm{F}_{\mathrm{yi}}^{\mathrm{A}}=A_{i} \sigma_{\mathrm{yd}} \\
\eta_{i}=\frac{\mathrm{F}_{\mathrm{yi}}^{\mathrm{D}}}{\mathrm{F}_{\mathrm{yi}}^{\mathrm{A}}} \\
\mathrm{u}_{\mathrm{yi}}^{B}=\mathrm{u}_{\mathrm{yi}}^{\mathrm{D}}+\eta_{\mathrm{i}} \mathrm{u}_{\mathrm{yi}}^{\mathrm{A}} \\
\mathrm{F}_{\mathrm{ui}}^{\mathrm{D}}=\mathrm{F}_{\mathrm{yi}}^{\mathrm{D}}+\mathrm{r}^{\mathrm{r}}\left(\mathrm{u}_{\mathrm{ui}}^{\mathrm{D}}-\mathrm{u}_{\mathrm{yi}}^{\mathrm{D}}\right)
\end{gathered}
$$

where: $\mathrm{F}_{\mathrm{yi}} \mathrm{A}^{\mathrm{A}}$ is the yielding force of the $\mathrm{i}$-th steel truss, $\sigma_{\mathrm{yd}}$ is the yielding stress of the steel adopted for the truss, $\eta_{\mathrm{i}}$ is the ratio between the yielding force of the $\mathrm{i}$-th dissipating device and the steel truss respectively, $\mathrm{u}_{\mathrm{yi}}{ }^{\mathrm{B}}$ is the yielding displacement of the $\mathrm{i}$-th brace, $\mathrm{u}_{\mathrm{yi}}{ }^{\mathrm{A}}$ is the yielding displacement of the $\mathrm{i}$-th steel truss, $\mathrm{F}_{\mathrm{ui}}{ }^{\mathrm{D}}$ is the maximum force

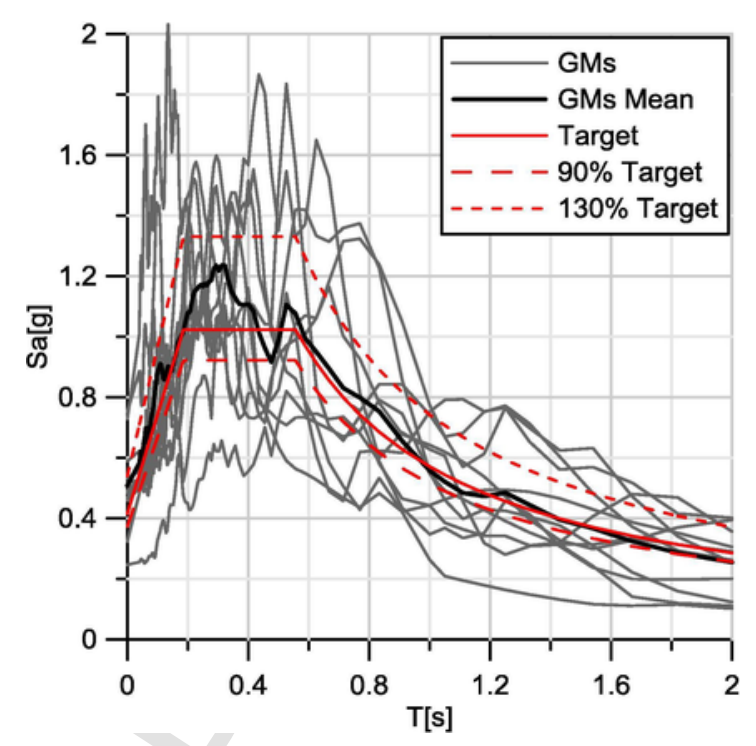

Fig. 9. GMs adopted for NL dynamic analyses. Single records, average and reference spectra for $\mathrm{T}_{\mathrm{r}}=975 \mathrm{yrs}$.

Table 1

Scale factors adopted for each hazard level.

\begin{tabular}{|c|c|c|c|c|c|c|c|}
\hline Tag & $\begin{array}{l}\text { Earthquake } \\
\text { name }\end{array}$ & Mw & $\begin{array}{l}\text { Fault } \\
\text { mechanism }\end{array}$ & $\begin{array}{l}\mathrm{R} \\
(\mathrm{kM})\end{array}$ & $\begin{array}{l}\text { Site } \\
\text { class }\end{array}$ & Date & $\begin{array}{l}\text { GM } \\
- \\
\text { Dir }\end{array}$ \\
\hline GM1 & $\begin{array}{l}\text { South } \\
\text { Iceland }\end{array}$ & 6.40 & strike slip & 5 & A & 2000 & $\mathrm{X}$ \\
\hline GM2 & Montenegro & 6.90 & thrust & 25 & B & 1979 & $\mathrm{Y}$ \\
\hline GM3 & Erzincan & 6.60 & strike slip & 13 & B & 1992 & $\mathrm{Y}$ \\
\hline GM4 & Gazli & 6.70 & thrust & 11 & $\mathrm{D}$ & 1976 & $\mathrm{Y}$ \\
\hline GM5 & Izmit & 7.60 & strike slip & 20 & C & 1999 & $\mathrm{X}$ \\
\hline GM6 & $\begin{array}{l}\text { South } \\
\text { Iceland }\end{array}$ & 6.50 & strike slip & 5.25 & A & 2000 & $\mathrm{Y}$ \\
\hline GM7 & Duzce & 7.10 & strike-slip & 5.27 & $\mathrm{C}$ & 1999 & $\mathrm{X}$ \\
\hline GM8 & Darfield & 7.10 & strike-slip & 17.82 & $C^{*}$ & 2010 & $\mathrm{X}$ \\
\hline GM9 & $\begin{array}{l}\text { Imperial } \\
\text { Valley }\end{array}$ & 6.50 & strike-slip & 27.03 & $\mathrm{C}$ & 1979 & $\mathrm{X}$ \\
\hline GM10 & Loma Prieta & 6.90 & oblique & 7.1 & B & 1989 & $\mathrm{X}$ \\
\hline GM11 & Northridge & 6.70 & reverse & 20.25 & $\mathrm{C}$ & 1994 & $\mathrm{X}$ \\
\hline
\end{tabular}

\begin{tabular}{lllll}
\hline $\operatorname{Tr}[\mathrm{yrs}]$ & 975 & 475 & 101 & 30 \\
\hline S.F. & 1.012 & 0.752 & 0.362 & 0.187 \\
\hline
\end{tabular}

Table 2

GMs characteristics.

of the $\mathrm{i}$-th brace, $\mathrm{u}_{\mathrm{ui}}{ }^{\mathrm{D}}$ is the maximum displacement of the $\mathrm{i}$-th device and $\mathrm{u}_{\mathrm{ui}}$ is the maximum displacement of the $\mathrm{i}$-th brace.

The non-linear behaviour of the brace is described through a linear equivalent scheme. Given the maximum displacement of the brace, $\mathrm{u}_{\mathrm{ui}}$, the stiffness properties of the brace are described through its secant stiffness, $K_{i}$, while the dissipating properties are described by its dissipated energy, $\mathrm{E}_{\mathrm{i}}$. If the displacement demand on the brace is lower than the yielding displacement (Fig. 3(a)), the brace behaves elastically, its stiffness can be determined through Eq. (7) and the energy dissipated is null. Contrarily, if the displacement demand is higher than the yielding displacement (Fig. 3(b)) the secant stiffness and the dissipated energy are calculated through Eq. (8). It should be noticed that the desired brace behaviour can only be obtained if the yielding force of the dissipator, $\mathrm{F}_{\mathrm{yi}}{ }^{\mathrm{D}}$, is lower than the yielding force of the steel truss, $\mathrm{F}_{\mathrm{yi}}{ }^{\mathrm{A}}$, i.e. if the parameter $\eta_{i}$ is lower than 1 . 

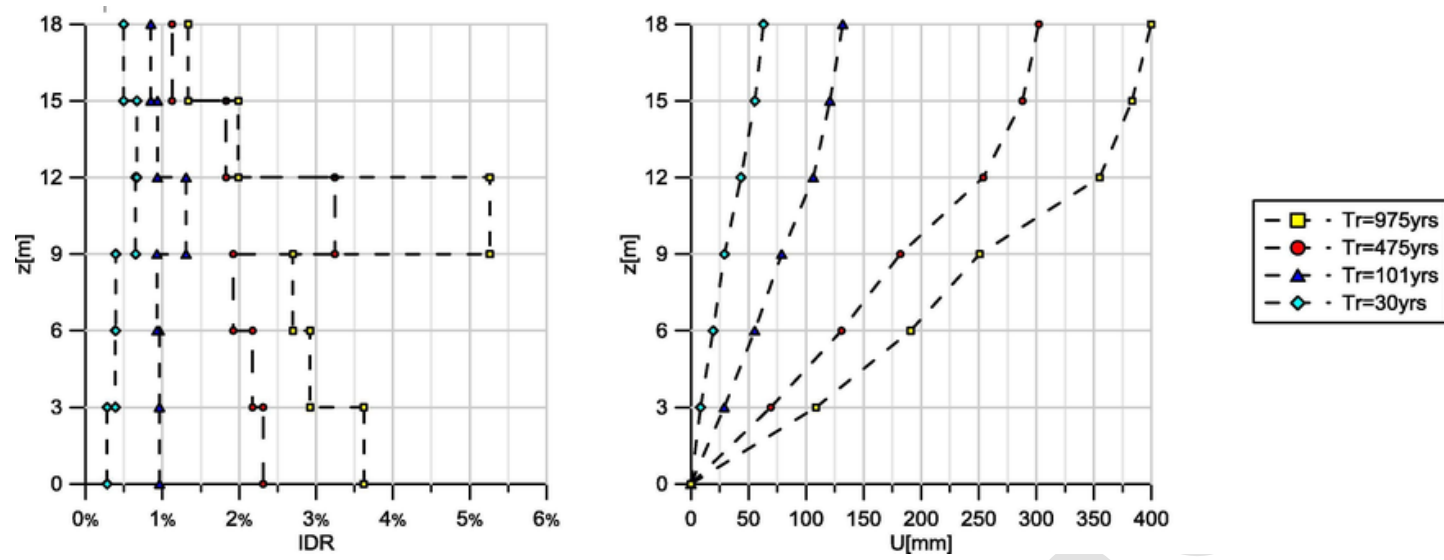

Fig. 10. Nonlinear dynamic analyses on the unbraced structure: average values of IDRs (a) and displacements (b) for each considered action level.

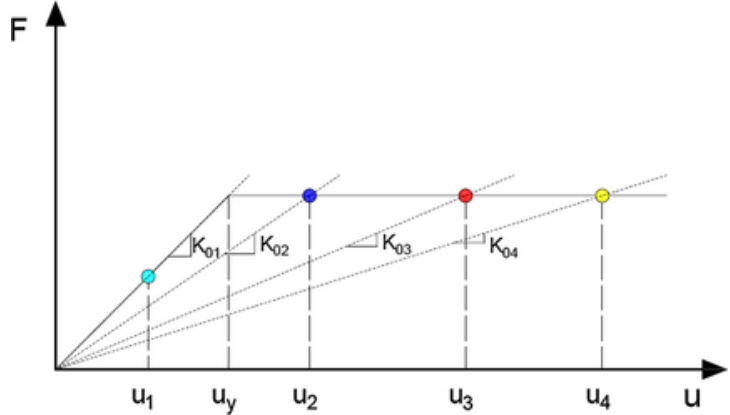

Fig. 11. Simplified Force-displacement relationship for the bare frame.

Such linearized properties depend on the independent variables values and on the displacement demand, $\mathrm{u}_{\mathrm{ui}}$, obtained from the structural analysis performed within the procedure. The linear equivalent characteristics of the brace are updated during the procedure and the convergence of the stiffness, the dissipated energy and the displacement demand is provided by specific sub-iterations, as summarized in Section 2.9 and in Fig. 9.

\subsection{Unbraced frame model and linearization}

For the reinforced concrete frame a bilinear behaviour is assumed, nevertheless, in order to perform linear analyses a linearization is foreseen and its behaviour is described within the procedure through an equivalent stiffness matrix, $\mathbf{K}_{\mathbf{0}}$, and an energy dissipated, $\mathrm{E}_{0}$. The stiffness matrix $\mathbf{K}_{\mathbf{0}}$ depends upon the final desired displacement of the retrofitted braced structure. If the desired deformation level keeps the structure mainly elastic, $\mathbf{K}_{\mathbf{0}}$ can be considered as the initial elastic stiffness matrix, $\mathbf{K}_{\mathrm{el}}$, while if the final deformation level foresees some damage on the frame, the starting stiffness matrix should properly describe the stiffness reduction (Fig. 4). The definition of the secant stiffness for the unbraced structure elements can be obtained through an iterative procedure or, as an alternative, through the Eq. (9), which is based on the global expected ductility demand Eq. (10). This latter method is very effective if used on new structures conceived with capacity design rules and where the collapse mechanism and the elements subjected to plasticization are known and specifically designed [31]. Clearly this is not the case of existing structures where the collapse mechanism is, generally, unknown, plasticizations are widely spread and brittle failures may occur. However, in the most common application cases, even for small ductility demands, the contribution of the unbraced frame to the global stiffness is very limited and therefore, even with an approximate evaluation, reliable results can be obtained.

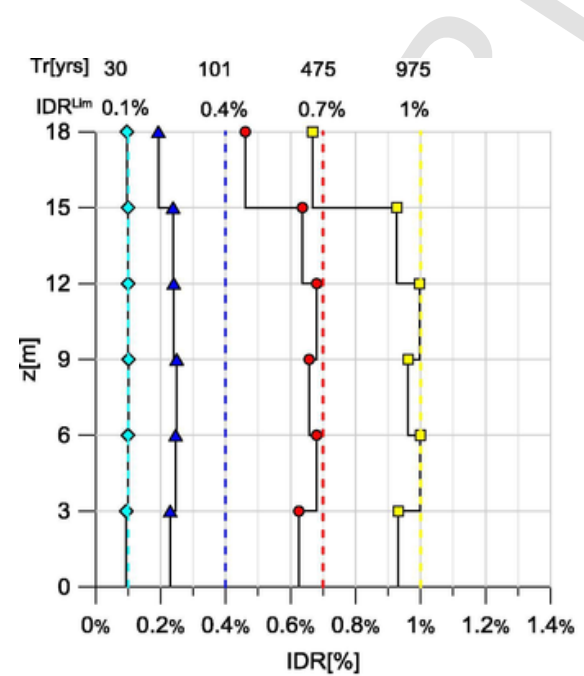

(a)

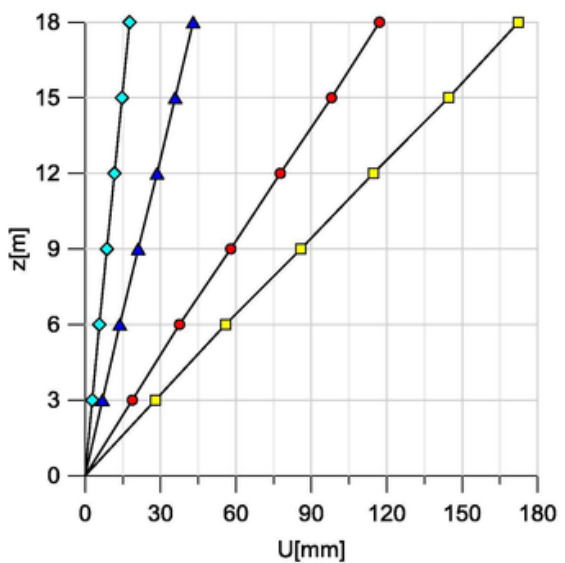

(b)

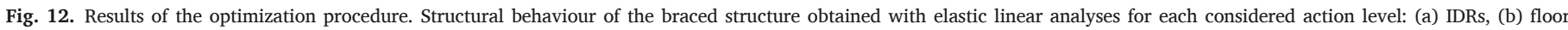
displacements. 


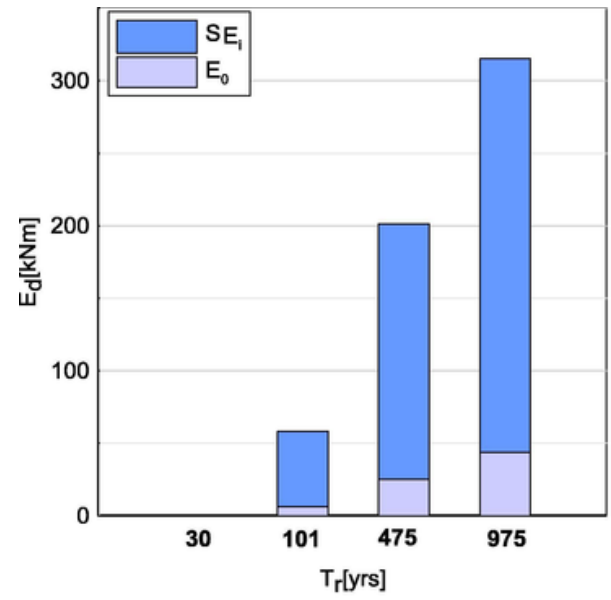

(a)

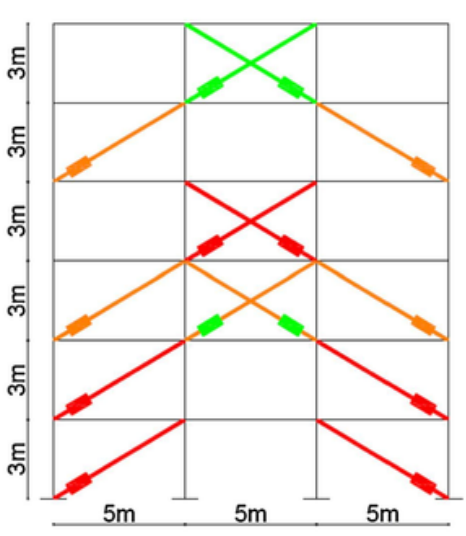

$$
\frac{A>30 \mathrm{~cm}^{2}<A<30 \mathrm{~cm}^{2}}{A<20 \mathrm{~cm}^{2}}
$$

$\mathrm{F}_{\mathrm{y}}>200 \mathrm{kN}$

$100 \mathrm{kN}<\mathrm{F}_{\mathrm{y}}<200 \mathrm{kN}$

$\mathrm{F}_{\mathrm{y}}<100 \mathrm{kN}$

(b)

Fig. 13. Results of the optimization procedure. (a) Energy dissipated by device $\left(\sum \mathrm{E}_{\mathrm{i}}\right)$ and by the unbraced frame $\left(\mathrm{E}_{0}\right)$ for each action level, (b) brace arrangement.

\begin{tabular}{|c|c|c|c|c|c|c|c|c|c|c|c|}
\hline $\mathrm{N}^{\circ}$ & A & $\mathrm{u}_{\mathrm{y}}$ & $\mathrm{F}_{\mathrm{y}}$ & $\mathrm{N}^{\circ}$ & A & $\mathrm{u}_{\mathrm{y}}$ & $\mathrm{F}_{\mathrm{y}}$ & $\mathrm{N}^{\circ}$ & A & $\mathrm{u}_{\mathrm{y}}$ & $\mathrm{F}_{\mathrm{y}}$ \\
\hline 1 & {$\left[\mathrm{~cm}^{2}\right]$} & {$[\mathrm{mm}]$} & {$[\mathrm{kN}]$} & 1 & {$\left[\mathrm{~cm}^{2}\right]$} & {$[\mathrm{mm}]$} & {$[\mathrm{kN}]$} & 1 & {$\left[\mathrm{~cm}^{2}\right]$} & {$[\mathrm{mm}]$} & {$[\mathrm{kN}]$} \\
\hline 1 & 35.41 & 0.22 & 256.18 & 13 & 23.00 & 0.20 & 138.78 & 25 & 26.30 & 0.22 & 162.75 \\
\hline 2 & 0.00 & - & 0.00 & 14 & 0.00 & - & 0.00 & 26 & 0.00 & - & 0.00 \\
\hline 3 & 0.00 & - & 0.00 & 15 & 20.56 & 0.22 & 97.19 & 27 & 0.00 & - & 0.00 \\
\hline 4 & 0.00 & - & 0.00 & 16 & 20.56 & 0.22 & 97.19 & 28 & 0.00 & - & 0.00 \\
\hline 5 & 0.00 & - & 0.00 & 17 & 0.00 & - & 0.00 & 29 & 0.00 & - & 0.00 \\
\hline 6 & 35.41 & 0.22 & 256.18 & 18 & 23.00 & 0.20 & 138.78 & 30 & 26.30 & 0.22 & 162.75 \\
\hline 7 & 38.14 & 0.20 & 289.09 & 19 & 0.00 & - & 0.00 & 31 & 0.00 & - & 0.00 \\
\hline 8 & 0.00 & - & 0.00 & 20 & 0.00 & - & 0.00 & 32 & 0.00 & - & 0.00 \\
\hline 9 & 0.00 & - & 0.00 & 21 & 30.58 & 0.20 & 241.64 & 33 & 14.72 & 0.22 & 77.55 \\
\hline 10 & 0.00 & - & 0.00 & 22 & 30.58 & 0.20 & 241.64 & 34 & 14.72 & 0.22 & 77.55 \\
\hline 11 & 0.00 & - & 0.00 & 23 & 0.00 & - & 0.00 & 35 & 0.00 & - & 0.00 \\
\hline 12 & 38.14 & 0.20 & 289.09 & 24 & 0.00 & - & 0.00 & 36 & 0.00 & - & 0.00 \\
\hline
\end{tabular}

Table 3

Results of the optimization procedure. Numerical values of independent variables.
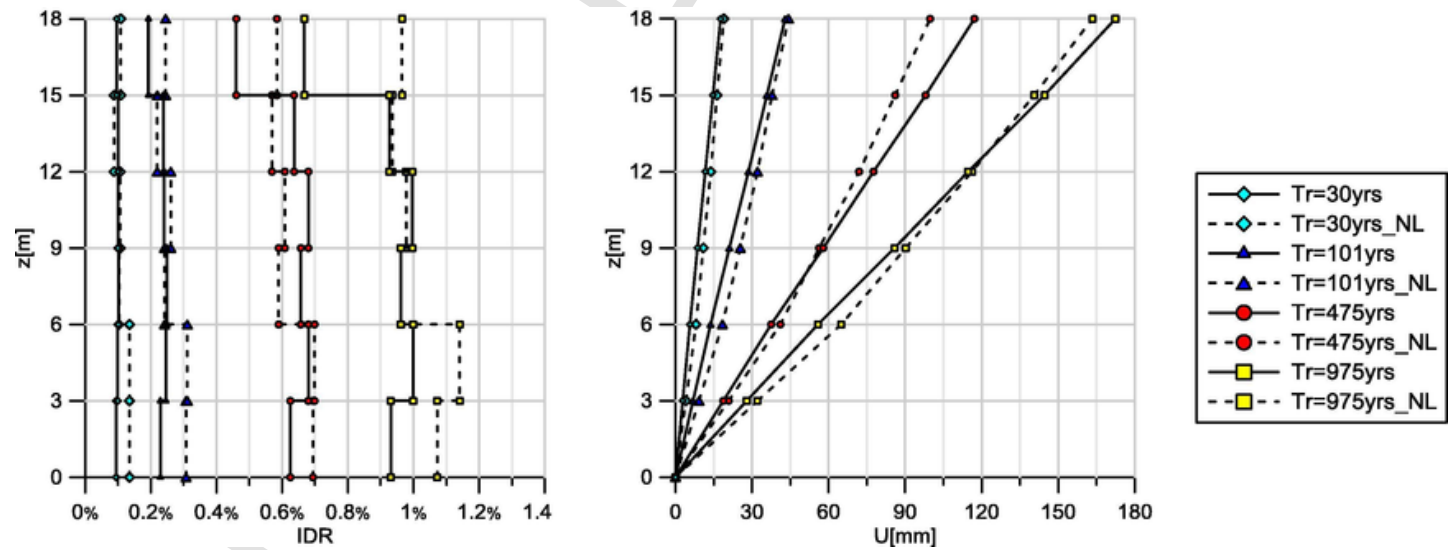

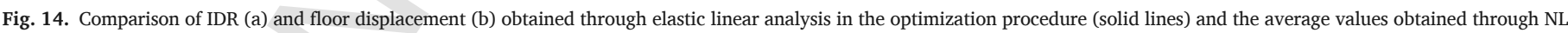
dynamic analyses (dashed lines).

Table 4

Cost amount of various items and total cost of intervention.

\begin{tabular}{lllll}
\hline Total cost & Steel & Dissipators & Foundation & Masonry \\
\hline$[€]$ & {$[€]$} & {$[€]$} & {$[€]$} & {$[€]$} \\
40444 & 7047 & 22026 & 2544 & 8827 \\
{$\left[€ / \mathrm{M}^{2}\right]$} & {$\left[€ / \mathrm{M}^{2}\right]$} & {$\left[€ / \mathrm{M}^{2}\right]$} & {$\left[€ / \mathrm{M}^{2}\right]$} & {$\left[€ / \mathrm{M}^{2}\right]$} \\
59.91 & 10.44 & 32.63 & 3.76 & 13.07 \\
\hline
\end{tabular}

Further, the problem of brittle failures is not discussed here and it is hypothesized that for the deformation levels required there are none. However, in future developments they may be taken into account or by evaluating the cost of local reinforcements or by using of appropriate constraints on forces/stresses as already proposed in [39]. 


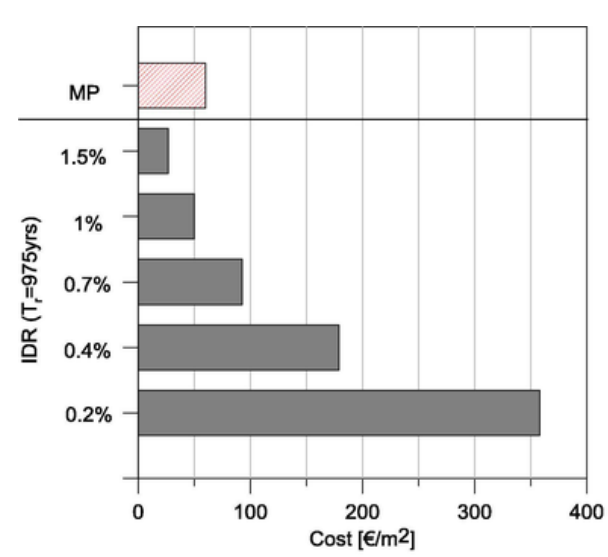

(a)

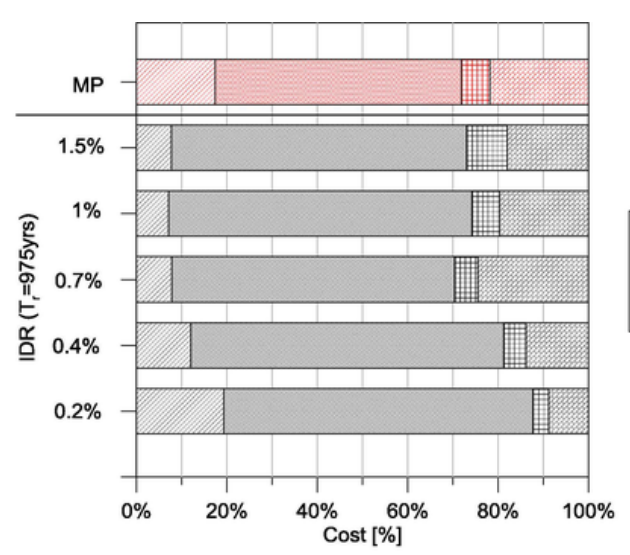

(b)

Fig. 15. Total intervention cost for different maximum IDR (a), Cost division for different maximum IDR (b).

$$
\begin{gathered}
\mathrm{K}_{\mathrm{i}}^{\mathrm{A}}=\frac{\mathrm{E}_{S} \mathrm{~A}_{\mathrm{i}}}{\mathrm{L}_{\mathrm{ii}}} \\
\mathrm{K}_{\mathrm{i}}^{\mathrm{D}}=\frac{\mathrm{F}_{\mathrm{yi}}^{\mathrm{D}}}{\mathrm{u}_{\mathrm{yi}}^{\mathrm{D}}} \\
\mathrm{K}_{\mathrm{i}}=\frac{\mathrm{K}_{\mathrm{i}}^{\mathrm{A}} \mathrm{K}_{\mathrm{i}}^{\mathrm{D}}}{\mathrm{K}_{\mathrm{i}}^{\mathrm{A}}+\mathrm{K}_{\mathrm{i}}^{\mathrm{D}}} \\
\mathrm{E}_{\mathrm{di}}=0 \\
\mathrm{~K}_{\mathrm{i}}^{\mathrm{A}}=\frac{\mathrm{E}_{S}}{\mathrm{~K}_{\mathrm{i}}^{\mathrm{D}}}=\frac{\mathrm{r}}{\mathrm{u}_{\mathrm{ui}}}=4\left(\mathrm{~F}_{\mathrm{yi}}^{\mathrm{D}} \mathrm{u}_{\mathrm{ui}}^{\mathrm{A}}\right. \\
\mathrm{K}_{\mathrm{i}}=\frac{\mathrm{K}_{\mathrm{i}}^{\mathrm{A}}}{\mathrm{A}} \\
E_{c} I_{i e q}=\frac{E_{c} I_{i}}{\mu} \\
\mu=\frac{\mathrm{u}_{\mathrm{d}}}{\mathrm{u}_{\mathrm{y}}}
\end{gathered}
$$

where: $E_{c}$ is the elastic modulus of concrete, $I_{i e q}$ is the equivalent inertia of the $\mathrm{i}$-th section, $I_{i}$ is the inertia of the $\mathrm{i}$-th section, $\mu$ is the global ductility demand, $\mathrm{u}_{\mathrm{d}}$ is the final displacement and $\mathrm{u}_{\mathrm{y}}$ is the yielding displacement of the frame.

\subsection{Assembly of the global stiffness matrix}

In order to be able to assess the structural response (i.e. the IDRs) of the braced structure, it is necessary to define how the stiffness matrix of the structure changes in the presence of the braces and with the variation of their characteristics. The advantage of adopting linear elastic models is that the stiffness contribution of the braces can simply be added to the terms of the frame stiffness matrix, considering appropriately the degrees of freedom on which they act. Thus, the stiffness matrix of the braced structure, $\mathbf{K}$, is formalized as the sum of the stiffness matrix of the unbraced structure, $\mathbf{K}_{\mathbf{0}}$, and the influence matrices, $\Delta \mathbf{K}_{\mathbf{i}}$, which represent the contribution of each brace to the global stiffness matrix [32]. These influence matrices $\Delta \mathbf{K}_{\mathbf{i}}$, whose components are all zero except for the components on which the brace has influence (Fig. 5), provide topological and dimensional information about the braces, as the matrix shape indicates the brace location in the structure while stiffness values are related to the equivalent stiffness, of each brace, $\mathrm{K}_{\mathrm{i}}$, obtained after the linearization procedure as exposed in Section 2.2.

$$
\begin{aligned}
& \mathbf{K}(\mathbf{x})=\mathbf{K}_{0}+\sum_{i=1}^{n} \Delta \mathbf{K}_{i}(\mathbf{x}) \\
& \text { 2.5. Equivalent damping ratio assessment }
\end{aligned}
$$

\subsection{Equivalent damping ratio assessment}

By considering the sum of the energy dissipated by each brace and the energy dissipated by the unbraced frame the equivalent damping ratio of the system is evaluated as follows

$\zeta_{e q}(\mathbf{x})=\frac{1}{4 \pi} \frac{\sum_{i=1}^{n} E_{d i}(\mathbf{x})+E_{0}}{E_{p}(\mathbf{x})}+\zeta_{v}$

where $E_{d i}(\mathbf{x})$ is the energy dissipated by the i-th brace, $E_{0}$ is the energy dissipated by the unbraced frame, $E_{p}(\mathbf{x})$ is the elastic energy of the braced structure and $\zeta_{\mathrm{v}}$ is the added viscous damping. Once known the damping ratio of the system, $\zeta_{\text {eq }}$, the seismic action is reduced using the following reduction factor $\gamma=\sqrt{10 /\left(5+\zeta_{\text {eq }}\right)}$.

\subsection{Acceptance criteria}

The acceptance criteria for the engineering demand parameters (EDPs) must be defined on the basis of the desired structural performance, in order to correctly formalize the constraint surfaces. In the proposed procedure, the interstory drift ratio (IDR) is considered. As known, the IDR is well correlated with damage on structural elements due to ductile mechanisms and with damage on non-structural elements (i.e. infills). The values of these IDR acceptance criteria are available in principal international codes [33-37] for both operating and ultimate limit states. However, such values arise from subjective and empirical evaluations and they do not result correlated with the effective building damages and repair costs, as pointed out in $[11,38]$. For these reasons acceptance criteria may be defined through consideration on economic losses and seismic risk levels obtained after the intervention as suggested in [39], or through considerations related to the building characteristics (e.g. operational requirements, properties of non-structural elements, brittle failures, maximum ductility capacity of structural elements).

In order to properly formalize the procedure, the acceptance criteria for IDRs are expressed by

$\mathbf{I D R}^{\mathrm{Lim}}=\left[\begin{array}{llll}\mathrm{IDR}_{1}^{\mathrm{Lim}} & \mathrm{IDR}_{2}^{\mathrm{Lim}} & \cdots & \mathrm{IDR}_{\mathrm{p}}^{\mathrm{Lim}}\end{array}\right]$

where: $\operatorname{IDR}_{i}{ }^{\mathrm{Lim}}$ is the maximum IDR for the $\mathrm{i}$-th floor and $\mathrm{p}$ is the number of floors. 


\subsection{Constraints}

The constraint functions correlate the EDPs with the acceptance criteria must be expressed as a function of the independent variables, thus the formalization of such functions depends upon the selected analysis method. In the following, the proposed formalization for a response spectrum linear dynamic analysis is shown, given a structure with $\mathrm{p}$ floors and by assuming a rigid diaphragm.

For each iteration step the stiffness matrix of the braced structure Eq. (11) is known, while the mass matrix is given as an input data. Modal participation factors, $\Gamma_{\mathbf{j}}$ Eq. (14), the accelerations, $\mathbf{a}_{\mathbf{j}}$, and the displacements, $\mathbf{u}_{\mathrm{j}}$, can be computed for the $\mathrm{j}$-th modal shape through modal shapes, $\phi_{j}$, and periods $\mathrm{T}_{\mathrm{j}}$

$\Gamma_{j}(\mathbf{x})=\frac{\phi_{j}^{\prime}(\mathbf{x}) \times \mathbf{M} \times \mathbf{B}}{\phi_{j}^{\prime}(\mathbf{x}) \times \mathbf{M} \times \phi_{j}(\mathbf{x})}$

$\mathbf{a}_{j}(\mathbf{x})=\phi_{j}(\mathbf{x}) \times \Gamma_{j}(\mathbf{x}) \times S_{a}\left(T_{j}(\mathbf{x})\right)$

$\mathbf{u}_{j}(\mathbf{x})=\phi_{j}(\mathbf{x}) \times \Gamma_{j}(\mathbf{x}) \times S_{d}\left(T_{j}(\mathbf{x})\right)$

where: $\phi_{j}^{\prime}$ is the transpose vector of the $\mathrm{j}$-th modal shape, $\mathbf{M}$ is the mass matrix, $B$ is the Boolean matrix, $S_{a}$ and $S_{d}$ are the spectral accelerations and displacement respectively.

The IDRs for the j-th mode can be calculated through Eq. (17) and collected for the k-th floor as expressed by Eq. (18)

$\operatorname{IDR}_{j, k}(\mathbf{x})=\frac{u_{j, k}(\mathbf{x})-u_{j, k-1}(\mathbf{x})}{h_{k}}$

$\operatorname{IDR}_{j}(\mathbf{x})$

$=\left[\begin{array}{lllll}\operatorname{IDR}_{j, 1}(\mathbf{x}) & \ldots & \operatorname{IDR}_{j, k}(\mathbf{x}) & \ldots & \operatorname{IDR}_{j, p}(\mathbf{x})\end{array}\right]$

The components of matrix Eq. (18) obtained for each mode are combined through a Complete Quadratic Combination (CQC) and recollected in Eq. (19)

$$
\begin{aligned}
& \operatorname{IDR}(\mathbf{x})=\left[\begin{array}{llll}
\sqrt{\sum_{l, m} \rho_{l m} \mathrm{IDR}_{l, 1} \mathrm{IDR}_{m, 1}} & \cdots & \sqrt{\sum_{l, m} \rho_{l m} \mathrm{IDR}_{l, k} \mathrm{IDR}_{m, k}} & \cdots
\end{array}\right. \\
& \rho_{l m}=\frac{8 \sqrt{\xi_{l} \xi_{m}}\left(\xi_{l}+\beta_{l m} \xi_{m}\right) \beta_{l m}^{1.5}}{\left(1-\beta_{l m}^{2}\right)+4 \xi_{l} \xi_{m} \beta_{l m}\left(1+\beta_{l m}^{2}\right)+4\left(\xi_{l}^{2}+\xi_{m}^{2}\right) \beta_{l m}^{2}}
\end{aligned}
$$

where: $\rho_{\mathrm{lm}}$ is the correlation coefficient between the 1 -th and the m-th mode, $\xi_{1}$ and $\xi_{\mathrm{m}}$ are the viscous damping of 1-th mode and $\mathrm{m}$-th mode respectively and $\beta_{\mathrm{lm}}$ is the ratio between the circular frequencies of 1-th and $\mathrm{m}$-th mode. For the sake of brevity, the dependence on independent variables is omitted in Eqs. (19) and (20).

By introducing Eqs. (13) and (19) in Eq. (1), the constraint equations can be expressed by means of the general optimization procedure definition Eq. (1).

\subsection{Objective function}

The objective function describes explicitly the cost of materials and works that influence the final cost of the intervention. It should be noticed that the final assessment of the total intervention cost is complex and goes beyond the goal of this work, however the proposed objective function keeps in count the principal items which have most impact on the intervention cost [40], and it is proposed as a useful tool in order to obtain an optimal bracing solution with a cost estimate close to reality, as well as a basic tool to perform a cost-benefit analysis for seismic risk assessments. By assuming the absence of brittle failures, therefore neglecting the need for local reinforcements, the considered cost items are the following: (a) steel elements (mainly truss and connections), (b) dissipative devices, (c) masonry works (removal and reconstruction or drillings and traces on infills), (d) foundation system improvement.

\section{(a) Steel elements}

By assuming the braces as reported in Fig. 1(a), the cost of the steel truss can be calculated by considering the total steel volume needed and its relative cost as

$C_{i}^{S}\left(A_{i}\right)=\beta_{1 i} \times A_{i}$

$\beta_{1 i}=\gamma_{s} \times c_{a} \times L_{1 i}$

where: $C_{i}^{S}$ is the cost function of the steel elements, $\beta_{1 i}$ is the cost coefficient for the $i$-th steel element, $\gamma_{s}$ is the volume weight of the steel and $c_{a}$ is the cost for weight-unit of the steel.

\section{(b) Dissipative devices}

The cost of a dissipative device strictly depends on its characteristics. In the case of elastoplastic devices, their cost depends on their dimension and dissipative capacities. An effective parameter to describe such characteristics is the yielding force of the device, as similarly proposed by Pollini et al. [23] for viscous fluid dampers. The cost function, proposed herein, can be expressed as

$C_{i}^{D}\left(F_{y i}^{D}\right)=\beta_{2 i} \times F_{y i}^{D}$

where: $C_{i}^{D}$ is the cost function for dissipative devices and $\beta_{2 i}$ is the cost coefficient for the $\mathrm{i}$-th dissipative device.

\section{(c) Masonry works}

Introducing new brace elements in existing reinforced concrete frames means, usually, the demolition and reconstruction of the infills. Due to the very high cost of such works, alternative solutions are adopted, as external bracing systems or bracing inserted inside the existing infill through the realization of drillings and traces. The latter solution is here adopted. In general, the cost of masonry works should be linked to the presence or not of the brace, leading to a non-continuous relationship (a zero function if the area of the brace is zero, conversely equal to the construction cost of the trace). However, in order to favour the problem convergence, an exponential function has been chosen. This function, although not convex, allows to consider a low cost for slender braces (whose area are as small as not to be significant in the design solution) and almost constant cost for larger braces. This approach is similar to the one proposed in Pollini et al. [23] that use an Heaviside function to minimize the number of different damper size-groups and the related cost of factory production test asked by modern seismic codes.

$C_{i}^{M}\left(A_{i}\right)=\beta_{3 i} \times\left(1-\exp \left(\alpha^{M} A_{i}\right)\right)$

where: $C_{i}^{M}$ is the cost function for masonry works $\beta_{3 \mathrm{i}}$ is the cost coefficient for the $\mathrm{i}$-th brace and $\alpha^{\mathrm{M}}$ is a coefficient which rules the shape of the function which has the dimension of the inverse of an area.

\section{(d) Foundation system}

One of the biggest issue when realizing a bracing retrofit intervention is the increment of the forces transmitted on the foundation system. Usually, the existing systems have not enough capacity to bear such increments. Among the different retrofit interventions on foundations, the insertion of micropile is one of the most adopted because of its effectiveness. In order to assess the cost of such intervention, it is as- 
sumed that the overload due to seismic action is totally supported by the micropiles, neglecting the reserve of capacity of existing foundation system. In this hypothesis, the cost of a single micropile is fixed and the number of micropiles needed is established on the basis of vertical discharge on each column. Given a structure with $n_{p}$ column, the relations between axial force at each base node, $\mathrm{N}_{\mathrm{m}} \mathrm{S}$, the resultant axial force of the braces converging at the base of each column, $\delta \mathrm{N}_{\mathrm{r}}$, the axial force at the base of each column, $\mathrm{N}_{\mathrm{r}}{ }^{\mathrm{f}}$ and the relative cost function $\mathrm{C}_{\mathrm{r}}{ }^{\mathrm{f}}$ are defined as

$N_{r}^{F}(\mathbf{x})=N_{r}^{S}(\mathbf{x})+\delta N_{r}(\mathbf{x})$

$C_{r}^{F}(\mathbf{x})=\beta_{4 r} \times N_{r}^{F}(\mathbf{x})$

where: $\beta_{4 \mathrm{r}}$ is the cost coefficient for the $r$-th column.

By using Eqs. (21), (23), (24) and (26), the global cost function can be expressed as

$$
\begin{gathered}
O . F .(\mathbf{x})=\sum_{i=1}^{n}\left(C_{i}^{S}\left(A_{i}\right)+C_{i}^{D}\left(F_{y i}^{D}\right)+C_{i}^{M}\left(A_{i}\right)+\sum_{r=1}^{n_{p}} C_{r}^{F}(\mathbf{x})\right. \\
\begin{aligned}
& O . F .(\mathbf{x})=\sum_{i=1}^{n}\left(\beta_{1 i} \times A_{i}+\beta_{2 i} \times F_{y i}^{D}+\beta_{3 i}\right. \\
& \times\left(1-\exp \left(\alpha^{M} A_{i}\right)\right)+\sum_{r=1}^{n_{p}} \beta_{4 r} \times N_{r}^{F}(\mathbf{x})
\end{aligned}
\end{gathered}
$$

\subsection{Resolution algorithm}

The resolution scheme adopted for the procedure is exposed in Fig. 6. The input data of the procedure are the initial stiffness, the energy dissipated and the mass matrix of the reinforced concrete frame (i.e. $\mathbf{K}_{\mathbf{0}}$, $\mathbf{M}_{0}$, $\left.E_{0}\right)$ ); further it is necessary to define an initial values vector for independent variables, $\mathbf{x}, \mathbf{y}_{\mathbf{0}}$, to be used as a trigger for the procedure and to assess an initial structural response. From this starting point, the procedure searches the independent variables $\mathbf{x},,_{\mathbf{j}}$ solution of the problem. Within the procedure and for each iteration, the interstory drift ratios, IDR, and local brace displacements, $\mathbf{u}_{\mathbf{u}}$, are calculated. The local displacements are used to find the linearized properties of the brace and some sub-iterations are needed in order to find convergence between the estimated displacements, and equivalent stiffness and damping .

The problem of the Eq. (1) is solved through the "Active-set" algorithm available in MATLAB ${ }^{\mathrm{TM}}$ [41], which is based on a Lagrange multiplier strategy and a quasi-Newton iterative method, while the Karush-Kuhn-Tucker (KKT) conditions are used for the solution to be optimal. By using this gradient-based algorithm, some convergence issues may arise, due to the non-convexity and non-linearity of the problem, thus some precautions must be taken in order to ensure the robustness of the solution. In general, the dependence of the final solution on the inital conditions $\mathbf{x}_{, 0}$, should be verified by varying widely and randomly $\mathbf{x}, \mathbf{0}$. However, for many practical cases, in order to avoid the convergence to a local minimum, for the choice of $\mathbf{x}_{\mathbf{0}}$, it is possible to adopt a two-step solution strategy. The first step consists in the resolution of a reduced problem with an objective function that includes only the steel costs $\left(\mathrm{C}_{\mathrm{i}}^{\mathrm{S}}\right.$, Eq. (21)). By minimizing such function a first indication on the brace arrangement that minimizes the added stiffness (i.e. the brace dimensions) on the system is obtained [42]. The solution obtained through this reduced problem is then used in the second step as the trigger for the resolution of the complete problem.

\section{Multiperformance design}

The optimization procedure exposed so far allows the sizing of a bracing system to obtain the desired structural performance and mini- mizing the cost of intervention for a given seismic action. However, the procedure can be easily extended to fulfil multiperformance design criteria, by controlling structural response for several action levels and by ensuring different acceptance criteria for each of them. Usually, one of the main challenges in these problems is to leave the same number of independent variables while resolving a higher number of structural problems. The definition of the independent variables allows to solve easily such problem and change the "singleperformance" optimization problem Eq. (1) into a "multiperformance" one.

The first step is the definition of the acceptance criteria, IDR ${ }^{\text {LimMP, }}$, for several action levels, in order to define the secant stiffness matrices, $\mathbf{K}_{0} \mathbf{M P}$, and the energy dissipated by unbraced frame, $\mathbf{E}_{\mathbf{0 M P}}$.

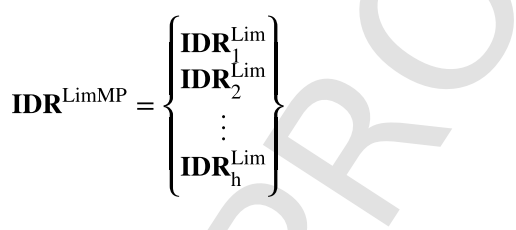

$\mathbf{K}_{0}^{\mathrm{MP}}=\left\{\begin{array}{c}\mathbf{K}_{01} \\ \mathbf{K}_{02} \\ \vdots \\ \mathbf{K}_{0 \mathrm{~h}}\end{array}\right\}$

$\mathbf{E}_{0}^{\mathrm{MP}}=\left\{\begin{array}{c}E_{01} \\ E_{02} \\ \vdots \\ E_{0 \mathrm{~h}}\end{array}\right\}$

where: $\mathrm{h}$ is the number of considered action levels, $\mathbf{I D R}_{\mathbf{h}}{ }^{\mathrm{Lim}}$ is the vector of maximum drift for the h-th action level, $\mathbf{K}_{\mathbf{0 h}}$ is the initial stiffness matrix for the $\mathrm{h}$-th action level and $\mathrm{E}_{0 \mathrm{~h}}$ is the energy dissipated by the frame for the h-th action level.

By using these input terms, within the optimization procedure, several global stiffness matrices for the braced structure, $\mathbf{K}_{\mathbf{h}}$, are assembled. The advantage of this representation is that the number of variables remain fixed and the stiffness matrices vary only by the way they are linearized, both for the fixed part $\mathrm{K}_{\mathbf{0 h}}$ and the variable part $\Delta \mathrm{K}_{\mathrm{hi}}$. In particular, the influence matrices $\Delta \mathrm{K}_{\mathrm{hi}}$ are assembled through the linearization procedure exposed in Section 2.2 by considering different displacement demands $\mathrm{u}_{\mathrm{ui}}$ on the braces while the independent variables are the same for each considered action level.

$\mathbf{K}^{\mathrm{MP}}(\mathbf{x})=\left\{\begin{array}{c}\mathbf{K}_{1}(\mathbf{x})=\mathbf{K}_{01}+\sum_{i} \Delta \mathbf{K}_{1 i}(\mathbf{x}) \\ \mathbf{K}_{2}(\mathbf{x})=\mathbf{K}_{02}+\sum_{i} \Delta \mathbf{K}_{2 i}(\mathbf{x}) \\ \vdots \\ \mathbf{K}_{h}(\mathbf{x})=\mathbf{K}_{0 h}+\sum_{i} \Delta \mathbf{K}_{h i}(\mathbf{x})\end{array}\right\}$

Once known the global stiffness matrices, the structural response can be computed as already shown in Section 2.7, to define the EDPs for each action level Eq. (33) and consequently formalize the constraint equations Eq. (34) and the multiperformance optimization problem Eq. (35).

$\operatorname{IDR}^{\mathrm{MP}}(\mathbf{x})=\left\{\begin{array}{c}\operatorname{IDR}_{1}(x) \\ \operatorname{IDR}_{2}(x) \\ \vdots \\ \operatorname{IDR}_{\mathrm{h}}(\mathbf{x})\end{array}\right\}$ 


$$
\begin{gathered}
\mathbf{h}_{\mathbf{1}}(\mathbf{x})=\operatorname{IDR}_{\mathbf{1}}(\mathbf{x})-\operatorname{IDR}_{1}^{\mathrm{Lim}} \\
\mathbf{h}_{\mathbf{2}}(\mathbf{x})=\operatorname{IDR}_{\mathbf{2}}(\mathbf{x})-\operatorname{IDR}_{\mathbf{2}}^{\mathrm{Lim}} \\
\vdots \\
\mathbf{h}_{\mathbf{h}}(\mathbf{x})=\operatorname{IDR}_{\mathbf{h}}(\mathbf{x})-\operatorname{IDR}_{\mathbf{h}}^{\mathrm{Lim}}
\end{gathered}
$$

$$
\min \begin{gathered}
O . F .(\mathbf{x}) \\
\left\{\begin{array}{c}
\mathbf{h}_{\mathbf{1}}(\mathbf{x})=\mathbf{I D R}_{\mathbf{1}}(\mathbf{x})-\mathbf{I D R}_{1}^{\mathrm{Lim}} \\
\mathbf{h}_{2}(\mathbf{x})=\mathbf{I D R}_{2}(\mathbf{x})-\mathbf{I D R}_{2}^{\mathrm{Lim}} \\
\vdots \\
\mathbf{h}_{h}(\mathbf{x})=\mathbf{I D R}_{h}(\mathbf{x})-\mathbf{I D R}_{h}^{\mathrm{Lim}}
\end{array}\right.
\end{gathered}
$$

\section{Numerical example}

In order to verify the effectiveness of the proposed optimization procedure, a six-story frame structure has been chosen as a case study (see Fig. 7). The case study represents a typical situation of existing structures, designed only for gravity loads and without capacity design principles, in which the tapering of the columns causes irregularities in elevation and potential formation of a weak plane at a level superior to the first. The story height is $3 \mathrm{~m}$, the beam span is $5 \mathrm{~m}$, the considered vertical load is $\mathrm{P}=10 \mathrm{kN} / \mathrm{m}^{2}$, and the considered floor mass is $112.5 \mathrm{kNs}^{2} / \mathrm{m}$. The beams have a $30 \times 50 \mathrm{~cm}$ section, external columns have a $30 \times 30 \mathrm{~cm}$ section and central columns are tapered along the building height: a $30 \times 60 \mathrm{~cm}$ has been considered for the first three floors while a $30 \times 30 \mathrm{~cm}$ section has been considered for the other three floors. The initial brace arrangement, shown in Fig. 8, foreseen 36 braces. The structure has been modelled in Sap2000 [43] in order to extrapolate geometric, stiffness and mass properties of the bare frame to be used as input for the optimization procedure. Furthermore, a specific model has been developed in OpenSees [44] in order to perform NL dynamic analyses. This model adopts concentrated plasticity elements (i.e. BeamWithHinges) to describe flexural nonlinear behaviour of beams and columns, steel elements are modelled through elastic truss and dissipating devices are modelled through Nonlinear link elements with hysteretic behaviour (i.e. Steel02). The effects of the brittle mechanisms, in particular of the beam-column joints, and the bond slip effects are not taken into consideration. Despite the relevance and the wide possibilities of modelling these aspects [45-50], it has been chosen to develop a numerical model coherent with the proposed procedure which, as discussed above, does not currently consider such phenomena. Moreover, unidirectional analyses are carried out without considering 3D effects. Regarding this aspect, it should be noticed that the design procedure allows the execution of 3D analyses by providing an appropriate set of constraints (i.e. constraints on floor drifts in two directions and/or floor rotations). The procedure is asked to find the optimal brace characteristics and disposition by considering 4 different action levels and performance levels. The initial conditions are first defined as uniform for all braces (i.e. $A_{i}=10 \mathrm{~cm}^{2}, F_{y i}{ }^{D}=263 k N, u_{y i}{ }^{D}=0.1 \mathrm{~cm}$ ), then these initial conditions are made to vary randomly in order to check the robustness of the final solutions and the independence from the initial trigger vector. In this case, given the small size of the problem, the two-step solution strategy is not adopted.

The reference elastic spectra are elaborated as defined by the Italian seismic code [36] by considering the hazard data of the site of "Reggio Calabria" (LAT 38.11, LON 15.66) for the return periods $\left(\mathrm{T}_{\mathrm{r}}\right.$ ) of 30, 101, 475 and 975 years, soil C and T1 site conditions. The "Reggio Calabria" site has been chosen as reference due to its high level of hazard and the availability of a GMs set properly selected in order to guarantee spectrum matching over an high range of frequencies $(0 \mathrm{~s}<\mathrm{T}<4 \mathrm{~s})$ [51]. Because of its characteristics, this set of 11 accelerograms has the advantage of being usable on structures whose behaviour is also very different, as commonly occurs on as-built and retrofitted buildings, giving the possibility to compare the structural responses in a more robust way. The GMs set has been selected considering a $\mathrm{Tr}=949 \mathrm{yrs}$, in order to obtain the spectrum coherence for the hazard levels considered herein, the records have been linearly scaled. GMs spectra, scale factors and characteristics of the records are exposed in Fig. 9, Tables 1 and 2, respectively.

In order to correctly define the desired performance of the braced structure, NL dynamic analyses have been performed on the unbraced structure. Fig. 10 shows the IDRs (Fig. 10a) and floor displacements (Fig. 10b) for the four different considered action levels. The displacement profile is not linear, producing an irregular IDR profile along the building height. In particular, the IDR at fourth floor $(z=9-12 \mathrm{~m})$ is significantly higher than in lower and upper floors due to the columns tapering and leads to a soft story mechanism. This effect is more significant for higher action levels with $\mathrm{T}_{\mathrm{r}}=475 \mathrm{yrs}$ and $\mathrm{T}_{\mathrm{r}}=975 \mathrm{yrs}$, where IDR at the fourth floor reaches values higher than $3 \%$ and $5 \%$, respectively. For these higher action levels, IDR profiles are irregular at lower floors too, where other soft story mechanisms may occur.

Basing on the unbraced structure behaviour assessment exposed above, the optimization procedure to design the bracing system has been defined as follows.

The initial stiffness matrices $\mathbf{K}_{\mathbf{0}}{ }^{\mathbf{M P}}$ are defined through the simplified model exposed in Section 2.3, the stiffness reduction coefficients $\boldsymbol{\mu}^{\mathrm{MP}}$ and the initial dissipated energies $\mathbf{E}_{\mathbf{o}} \mathbf{M P}$ are evaluated by considering the yielding rotation $\theta_{\mathrm{y}}$, in this case equal to $0.3 \%$, and the target displacements derived from target drifts Eq. (37) as shown in Fig. 11.

$$
\begin{aligned}
& \boldsymbol{\mu}^{\mathrm{MP}}=\left\{\begin{array}{c}
0 \\
0.75 \\
0.43 \\
0.3
\end{array}\right\} \quad \mathbf{E}_{\mathbf{0}}^{\mathrm{MP}}[\mathrm{kNm}]=\left\{\begin{array}{c}
0 \\
6.2 \\
25.0 \\
43.7
\end{array}\right\} \\
& \mathbf{u}^{\mathrm{Lim}}[\mathrm{cm}]=\left\{\begin{array}{l}
u_{1} \\
u_{2} \\
u_{3} \\
u_{4}
\end{array}\right\} \\
&=\left\{\begin{array}{c}
1.8 \\
7.2 \\
0.126 \\
0.18
\end{array}\right\} \quad \mathbf{I D R}^{\mathrm{Lim}} \\
&=\left\{\begin{array}{c}
0.1 \% \\
0.4 \% \\
0.7 \% \\
1 \%
\end{array}\right\}
\end{aligned}
$$

The objective function Eq. (38) is a specialized expression of Eq. (28), by considering $\beta 1=0.032 € / \mathrm{cm}^{3} \quad\left(\gamma_{\mathrm{s}}=7850 \mathrm{~kg} / \mathrm{m}^{3}\right.$, $\left.\mathrm{c}_{\mathrm{a}}=4.07 € / \mathrm{kg}\right), \quad \beta_{2}=8.71 € / \mathrm{kN}, \quad \beta_{3}=625 €, \quad \beta_{4}=1.65 € / \mathrm{kN}$, $\alpha^{\mathrm{M}}=-0.5 \mathrm{~cm}^{-2}$. These unitary costs are evaluated with the price list of the Regione Abruzzo (Italy) [50].

$$
\begin{aligned}
\text { O.F.I.C. }=\sum_{i=1}^{36}( & .032 \times L_{i} \times A_{i}+8.71 \times F_{y i}^{D}+625 \\
& \times\left(1-\exp \left(-0.5 A_{i}\right)\right)+\sum_{m=1}^{4} 1.65 \times N_{m}^{f}
\end{aligned}
$$

Fig. 12 shows the results obtained through the optimization procedure in terms of IDRs, floor displacements, brace arrangement and energy dissipated, given the uniform initial conditions. The solution was found after 47 iterations and 5319 function evaluations. The displacement profile (Fig. 12b) is almost linear for all the considered action levels, leading to an IDR profile (Fig. 12a) almost constant, ensuring a regular structural behaviour and removing all the weak story mechanisms found at first and fourth floor in the analyses of the unbraced structure. 
Absolute values of IDRs are very close to the imposed limit, apart from the action level with $\mathrm{T}_{\mathrm{r}}=101 \mathrm{yrs}$ where IDR values vary between $0.2 \%$ and $0.3 \%$, lower than the requested value of $0.4 \%$. This is due to the need of a very high stiffness to obtain the desired IDR for $T_{r}=30 y r s$ that lead to the impossibility to obtain a much higher drift for a slightly higher level of action. In Fig. 13(a) the hysteretic energy dissipated calculated within the procedure by the devices $\left(\sum \mathrm{E}_{\mathrm{i}}\right)$ and the energy dissipated by the frame $\left(E_{0}\right)$ are shown. It can be noticed that the hysteretic energy dissipated by braces increases for higher action levels and displacements, in particular both devices and frame remain elastic for $\mathrm{T}_{\mathrm{r}}=30 \mathrm{yrs}$ while already for an action with $\mathrm{T}_{\mathrm{r}}=101 \mathrm{yrs}$ the devices dissipate a small quantity of energy even if the frame behaves almost elastic. In this regard, it should be noted that the stiffness and the energy dissipated by the braces are evaluated in step within the procedure and are then coherent with the real deformation level of each brace, while stiffness and energy dissipated by the frame are imposed upstream. Finally, Fig. 13(b) shows the brace arrangement obtained through the procedure: of the 36 braces initially assumed only 14 are considered for the optimal solution, their disposition is characterized by single diagonal braces in external spans and cross diagonal braces in central spans at higher floors. The numerical solution is shown in Table 3. From the results, it can be seen that brace areas (A) and yielding forces (Fy) reduce along the height of the building, except for the fourth floor where the braces are slightly stiffer than in the adjacent floors, in order to contain the elevation irregularity. The yielding displacement $\left(\mathrm{u}_{\mathrm{y}}\right)$, remains almost constant for all the braces leading to an almost contemporary yielding of the devices, considering the uniform drift profile and span lengths.

In order to check the effectiveness of the linearization procedure and validate the results of the optimization procedure, NL dynamic analyses have been performed on the braced structure. Fig. 14 shows the comparison, in terms of IDRs and floor displacements, between the results obtained with the optimization procedure and the average values obtained through NL dynamic analyses on the braced structure. Displacement profiles (Fig. 14b) are almost linear for all the action levels leading to almost uniform IDRs (Fig. 14a) along the building height. Nevertheless, absolute values of displacements and IDRs are in good agreement between the two different analyses. These results show how the linearization procedure allows a reliable assessment of the structural performance.

The proposed procedure allows to obtain the desired structural performance by limiting the IDRs values and suggests an optimal plan and elevation brace arrangement by minimizing the intervention costs. With this regard, more observations can be made on the usefulness of the procedure.

Table 4 shows the final intervention cost for the case study structure both in terms of absolute values and cost per unit of area (i.e. $€ / \mathrm{m}^{2}$ ). The voice that has a major impact on the final cost is the cost of dissipators (i.e. $32.63 € / \mathrm{m}^{2}$ ), followed by masonry works (i.e. $13.07 € / \mathrm{m}^{2}$ ), steel trusses (i.e. $10.44 € / \mathrm{m}^{2}$ ) and new foundation systems (i.e. $3.76 € / \mathrm{m}^{2}$ ). The impact of energy dissipation devices is particularly high due to the high unitary cost of the devices provided by the adopted price list [52] which is, anyway, one of the fewer reference for cost assessment of such devices in Italy and Europe. Masonry works impact for over $20 \%$ of the total cost, even if only the making of a narrow trace to insert the brace is considered, instead of a complete removal and rebuilding of the panel. Such a result confirms that, when possible, external bracing is useful to mitigate intervention costs even if, as a counterpart, external bracing needs more complex connections to the frame that may increase their costs, besides several architectural issues. Steel cost impacts for $17 \%$ and foundation systems interventions impact on only $6 \%$ of the total cost. This can be explained by considering that the brace arrangement obtained through the procedure distribute the vertical load among the 4 columns and concentrate the axial load on external columns. This specific brace arrangement allows the minimization of "rocking" effects and consequently the reduction of maxi- mum axial load on foundations, providing an optimal solution in this sense, too. Further, it should be observed that, due to the relative higher cost of the dissipating devices, the optimization procedure automatically leads to solutions with exuberant truss dimensions with respect to the dimensions of the dissipator, guaranteeing in such a way the linear behaviour of the truss without the need of a specific constraint.

Considering the significant performance improvement described above, the intervention cost seems to be reasonable and sensibly lower than other bracing interventions realized in Italy [53-54] even if it should be noted that the estimated cost does not consider many other cost items (e.g. other local reinforcements, connections to building, excavations and drillings, transport to landfill etc.). Despite this necessary clarification, the proposed objective function allows to make critical evaluations of relationship between interventions cost and performance improvement. Fig. 15 shows a comparison between the total intervention cost (Fig. 15a) and its percental distribution among the different cost items (Fig. 15b) obtained with the multiperformance optimal design ("MP") and five other singleperformance design obtained on the same structure, asking for the achievement of an unique performance level (i.e. IDR $=0.2 \% ; 0.4 \% ; 0.7 \%, 1 \% ; 1.5 \%$ ) for an action level with $\mathrm{T}_{\mathrm{r}}=975 \mathrm{yrs}$. It can be noticed that the cost variation is extremely high. In particular, in order to obtain an elastic behaviour of the concrete frame (i.e. IDR $0.2 \%$ ) the intervention cost is higher than $350 € / \mathrm{m}^{2}$, about 7 times higher than the cost obtained through multiperformance design. By reducing the requested performance level (i.e. increasing the requested IDR) the costs are gradually lower. It should be observed that an IDR $=1 \%$ for a $\mathrm{T}_{\mathrm{r}}=975 \mathrm{yrs}$ is obtained through the multiPerformance problem, with a cost of about $59 € / \mathrm{m}^{2}$, while by solving a singleperformance problem with the same IDR request the cost is about $50 € / \mathrm{m}^{2}$. It is noticeable that the cost repartition among the various items is significantly different, even though the final cost is similar, as it can be seen by comparing the results of "MP" and "1\%" problem (Fig. 15b) where the steel cost is significantly higher in the case of the multiperformance problem due to the high stiffness request for lower action levels that leads to stiffer and heavier steel trusses. With a small cost increase it is possible to control the structural performance for other three action levels, in particular, it is possible to explicitly control that the structure behave elastic or almost elastic for more frequent action, compatibly with operational and reduced damage limit states performance request, while allowing moderate yieldings for rare action levels guaranteeing life safety and collapse prevention, all through a minimally invasive, lighter and cheaper intervention. Furthermore, the proposed objective function allows to made a comparison in terms of cost/ benefit ratio between the requested performance and the intervention costs, by considering the easiness of input data and its reduced computational effort for multiperformance problems too.

\section{Conclusions}

The proposed procedure allows the design of a bracing system by controlling the structural response through a multiperformance approach while minimizing the intervention costs. This procedure is based on elastic linear analysis, keeping in count the nonlinear behaviour of both braces and frame through visco-elastic equivalent linear schemes. The results of the numerical example show how the procedure finds the characteristics of a bracing system in order to obtain the desired structural response, using simple elastic linear analyses, on an irregular structure, too. The comparison with NL dynamic analyses has proven the effectiveness of such schemes to predict the structural response, guaranteeing a reliable bracing design but strongly reducing the computational effort. Further, on the basis of an initial brace arrangement, the procedure is capable to find the optimal brace disposition, besides the mechanical properties of each brace. The cost intervention analysis has highlighted how the proposed objective function provides useful indications for the choice of target performance 
level, allowing a rapid comparison between structural behaviour and intervention invasiveness. In this regard, it has been observed that the intervention cost may vary up to 7 times by varying the target IDRs. Furthermore, it has been show how, given a small cost increment (less than $20 \%$ ), while guaranteeing the same performance in terms of life safety or collapse prevention, the multiperformance problem allows to obtain an explicit control of the structural response for more frequent events which mostly impacts the seismic risk assessment of the building.

In conclusion, the proposed procedure allows to obtain an optimal bracing design through a traditional multiperformance approach, based only on checking of structural performance through a comparison between engineering demand parameters and acceptance criteria with a computational effort more suited to a design procedure, without the need of NL analyses. Moreover, by using the intervention cost as an optimality criterion, the procedure allows to perform a cost-benefit assessment and opens up to its use also in the context of risk-based design methodologies. Finally, it should be noted that such methodological approach which overlaps older and newer performance based design approaches to design is adaptable to many other fields or applications other than braces and can therefore be understood as a general design approach.

\section{Appendix A. Supplementary material}

Supplementary data to this article can be found online at https:// doi.org/10.1016/j.engstruct.2018.12.034.

\section{References}

[1] D.F. D'Ayala, S. Paganoni, Assessment and analysis of damage in L'Aquila historic city centre after 6th April 2009, Bull Earthq Eng 9 (2011) 81-104, https://doi.org/ 10.1007/s10518-010-9224-4.

[2] F. Braga, V. Manfredi, A. Masi, A. Salvatori, M. Vona, Performance of non-structural elements in RC buildings during the L'Aquila, 2009 earthquake, Bull Earthq Eng 9 (2011) 307-324, https://doi.org/10.1007/s10518-010-9205-7.

[3] B. Khazai, J.E. Daniell, F. Wenzel, The March 2011 Japan Earthquake, TATuP - J Technol Assess Theory Pract 20 (2011) 22-33.

[4] W.Y. Kam, S. Pampanin, K. Elwood, Seismic performance of reinforced concrete buildings in the 22 February Christchurch (Lyttelton) earthquake, Bull N Zeal Soc Earthq Eng 44 (2011) 239-278.

[5] Celano F, Cimmino M, Coppola O, Magliulo G, Salzano P. Report dei danni registrati a seguito del terremoto del Centro Italia del 24 Agosto 2016. Reluis; 2016.

[6] M. Di Ludovico, A. Prota, C. Moroni, G. Manfredi, M. Dolce, Reconstruction process of damaged residential buildings outside historical centres after the L'Aquila earthquake: part I- "light damage" reconstruction, Bull Earthq Eng 15 (2017) 667-692, https://doi.org/10.1007/s10518-016-9979-3.

[7] M. Di Ludovico, A. Prota, C. Moroni, G. Manfredi, M. Dolce, Reconstruction process of damaged residential buildings outside historical centres after the L'Aquila earthquake: part II- "heavy damage" reconstruction, Bull Earthq Eng 15 (2017) 693-729, https://doi.org/10.1007/s10518-016-9979-3.

[8] I.A. Zambrano, I.F. Bonfà, I.G. Massa, I.R. Pellegatta, I.M. Lapenna, I costi dei terremoti in Italia, Centro Studi Consiglio Nazionale Ingegneri, Roma, 2014.

[9] R. Muir-Woods, The Christchurch earthquakes of 2010 and 2011, in: C. Courbage, W.R. Stahel (Eds.), Geneva Reports Extreme Events and Insurance: 2011 Annus Horribilis, The geneva Association Risk \& Insurance Economics, Geneva, 2012, pp. 93-106.

[10] J. Moehle, G.G. Deierlein, A framework methodology for performance-based earthquake engineering, 13th World Conf. Earthq. Eng., 2004.

[11] A. Whittaker, R. Hamburger, M. Mahoney, Performance-based engineering of buildings for extreme events, In: AISC-SINY Symp. Resist. Blast Progress, American institute of Steel Construction, Collapse, New York, 2003, pp. 55-66.

[12] Applied Technology Council, FEMA P-58-1 Seismic Performance Assessment of Buildings - Methodology, vol. 1, Federal Emergency Management Agency (FEMA), Washington D.C., 2012.

[13] F. Braga, F. Morelli, W. Salvatore, A macroseismic approach for the evaluation of seismic risk, in: J. Kruis, Y. Tsompanakis, B. Topping (Eds.), Fifteenth Int. Conf. Civil, Struct. Environ. Eng. Comput., Prague, 2015, pp. 1-12.

[14] A. Dall'Asta, G. Leoni, F. Morelli, W. Salvatore, A. Zona, An innovative seismic-resistant steel frame with reinforced concrete infill walls, Eng Struct 141 (2017) 144-158, https://doi.org/10.1016/j.engstruct.2017.03.019.

[15] A. Braconi, F. Morelli, W. Salvatore, Development, design and experimental validation of a steel self-centering device (SSCD) for seismic protection of buildings, Bull Earthq Eng 10 (2012) 1915-1941, https://doi.org/10.1007/s10518-012-9380-9.

[16] C. Christopoulos, R. Tremblay, H.-J. Kim, M. Lacerte, Self-centering energy dissipative bracing system for the seismic resistance of structures: development and vali- dation, J Struct Eng 134 (2008) 96-107, https://doi.org/10.1061/ (ASCE)0733-9445(2008) 134:1(96).

[17] A. Filiatrault, S. Cherry, Seismic design spectra for friction damped structures, J Struct Eng 116 (1990) 1334-1355.

[18] F. Braga, P. D’Anzi, Steel braces with energy absorbing devices: a design method to retrofit reinforced concrete existing buildings, Proc. Ital. Symp. Strength. Repair Struct. Seism. Area, Nice, 1994.

[19] V. Ciampi, M. De Angelis, F. Paolacci, Design of yielding or friction-based dissipative bracings for seismic protection of buildings, Eng Struct 17 (1995) 381-391, https://doi.org/10.1016/0141-0296(95)00021-X.

[20] I. Takewaki, Optimal damper placement for minimum transfer functions, Earthq Eng Struct Dyn 26 (1997) 1113-1124.

[21] R. Levy, E. Marianchik, A. Rutenberg, F. Segal, Seismic design methodology for friction damped braced frames, Earthq Eng Struct Dyn (2000) 1569-1585.

[22] O. Lavan, G.F. Dargush, Multi-objective evolutionary seismic design with passive energy dissipation systems multi-objective evolutionary seismic design with passive energy dissipation systems, J Earthq Eng (2009) 37-41, https://doi.org/10. $1080 / 13632460802598545$

[23] N. Pollini, O. Lavan, O. Amir, Towards realistic minimum-cost optimization of viscous fluid dampers for seismic retrofitting, Bull Earthq Eng 14 (2016) 971-998, https://doi.org/10.1007/s10518-015-9844-9.

[24] N. Pollini, O. Lavan, O. Amir, Minimum-cost optimization of nonlinear fluid viscous dampers and their supporting members for seismic retrofitting, Earthq Eng Struct Dyn 46 (2017) 1941-1961, https://doi.org/10.1002/eqe.

[25] O. Lavan, P.J. Wilkinson, Efficient seismic design of 3D asymmetric and setback RC frame buildings for drift and strain limitation, J Struct Eng 143 (2017) 1-12, https://doi.org/10.1061/(ASCE)ST.1943-541X.0001689.

[26] J.A. Inaudi, J.M. Kelly, C.W.S. To, Statistical linearization method in the preliminary design of structures with energy dissipating devices, ATC 17-1 (1993) 509-520.

[27] Y. Fu, S. Cherry, Design of friction damped structures using lateral force procedure, Earthq Eng Struct Dyn (2000) 989-1010.

[28] O.M. Ramirez, M.C. Constantinou, A.S. Whittaker, C.A. Kircher, M.W. Johnson, C.Z. Chrysostomou, Validation of the NEHRP Provisions' equivalent lateral force and modal analysis procedures for buildings with damping systems, Earthq Spectra 2003 (19) (2000) 981-999, https://doi.org/10.1193/1.1622392.

[29] F. Mazza, A. Vulcano, Equivalent viscous damping for displacement-based seismic design of hysteretic damped braces for retrofitting framed buildings, Bull Earthq Eng 12 (2014) 2797-2819, https://doi.org/10.1007/s10518-014-9601-5.

[30] J. Wen, W. Guo, C. Christopoulos, Performance spectra based method for the seismic design of structures equipped with passive supplemental damping systems, Earthq Eng Struct Dyn (2013) 935-952, https://doi.org/10.1002/eqe.

[31] M.J.N. Priestley, Performance based seismic design, In: 12th WCEE, vol. 1, 2000, pp. 1-22.

[32] N. Bonessio, Ottimizzazione strutturale su base prestazionale di sistemi di controventi dissipativi, [PhD Thesis] University of Rome La Sapienza, 2009.

[33] American Society of Civil Engineers, FEMA-356 Prestandard and commentary for the seismic rehabilitation of buildings, Federal Emergency Management Association (FEMA), Washington D.C., 2000.

[34] ASCE/SEI 7-10, Minimum design loads for buildings and other structures, American Society of Civil Engineers, Reston, 2010.

[35] EN1998:1, Eurocode 8: design of structures for earthquake resistance - Part 1: general rules, seismic actions and rules for buildings, European Committe for Standardization, Bruxelles, 2005

[36] D.M. 14.01.08 Norme Tecniche per le costruzioni. Rome: Italian Ministry of Infrastructure; 2008.

[37] D.M. 17.01.18 Aggiornamento delle "Norme Tecniche per le costruzioni." Rome: Italian Ministry of Infrastructure; 2018.

[38] R.O. Hamburger, A vision for performance based earthquake engineering, Unpublished white paper for Applied Technology council, Redwood City, 2003.

[39] Laguardia R. Una, Procedura di Ottimizzazione Multi-Prestazionale per la Riduzione del Rischio Sismico attraverso Sistemi di Controventi Elastici e Dissipativi, [PhD Thesis] University of Rome La Sapienza, 2016.

[40] Research Fund for Coal and Steel, Steel solutions for seismic retrofit and upgrade of existing constructions (Steelretro) - Final report, European Commission, Luxembourg, 2013.

[41] MathWorks Inc. MATLAB: the language of technical computing: computation, visualization, programming R2017b. Natwick: Math Works Inc., 1996; 2017.

[42] R. Laguardia, R. Gigliotti, F. Braga, Optimal design of dissipative braces for seismic retrofitting through a multi- performance procedure, Seism. Eng. Italy ANIDIS 2017, Pistoia, 2017.

[43] Computers and Structures Inc. SAP2000 Integrated solution for strucutral analysis \& design; 2015

[44] S. Mazzoni, F. McKenna, M.H. Scott, G.L. Fenves, OpenSees command language manual, Pacific Earthq Eng Res Cent (2007) 451.

[45] M. Laterza, M. D'Amato, R. Gigliotti, Modeling of gravity-designed RC sub-assemblages subjected to lateral loads, Eng Struct 130 (2017) 242-260, https://doi.org/ 10.1016/j.engstruct.2016.10.044.

[46] M. Laterza, M. D'Amato, F. Braga, R. Gigliotti, Extension to rectangular section of an analytical model for concrete confined by steel stirrups and/or FRP jackets, Compos Struct 176 (2017) 910-922, https://doi.org/10.1016/j.compstruct.2017. 06.025 .

[47] A.F. Mohammad, M. Faggella, R. Gigliotti, E. Spacone, Effects of bond-slip and masonry infills interaction on seismic performance of older R/C frame structures, Soil Dyn Earthq Eng 109 (2018) 251-265, https://doi.org/10.1016/j.soildyn.2018.02. 027 
[48] S. Caprili, F. Mattei, R. Gigliotti, W. Salvatore, Modified cyclic steel law including bond-slip for analysis of RC structures with plain bars, Earthq Struct 14 (2018) 187-201.

[49] F. Romano, M. Faggella, R. Gigliotti, M. Zucconi, B. Ferracuti, Comparative seismic loss analysis of an existing non-ductile RC building based on element fragility functions proposals, Eng Struct 177 (2018) 707-723, https://doi.org/10.1016/j. engstruct.2018.08.005.

[50] A.F. Mohammad, M. Faggella, R. Gigliotti, E. Spacone, Seismic performance of older R/C frame structures accounting for infills-induced shear failure of columns, Eng Struct 122 (2016) 1-13, https://doi.org/10.1016/j.engstruct.2016.05.010.

[51] F. Morelli, R. Laguardia, M. Faggella, A. Piscini, R. Gigliotti, W. Salvatore, Ground motions and scaling techniques for 3D performance based seismic assessment of an industrial steel structure, Bull Earthq Eng 16 (2018) 1179-1208, https://doi.org/ 10.1007/s10518-017-0244-1.

[52] Servizio tecnico regionale dei LL.PP, Prezzi Informativi opere edili della regione Abruzzo, Giunta regionale regione Abruzzo, L'Aquila (IT), 2014.

[53] Neri F, Spampinato G. Studio dello stato dell'arte e di diffusione di tecniche di intervento innovative in zone ad elevato rischio sismico. Catania (IT); 2009.

[54] Dolce M, Manfredi G, editors. Libro bianco sulla ricostruzione privata fuori dai centri storici nei comuni colpiti dal sisma dell'Abruzzo del 6 Aprile 2009. Rome (IT); 2015. 